Article

\title{
Metropolitan Innovation and Sustainability in China-A Double Lens Perspective on Regional Development
}

\author{
Xiangdong Chen ${ }^{1}$, Ruixi $\mathrm{Li}^{1, *}$, Xin Niu ${ }^{1}$, Ulrich Hilpert ${ }^{2}$ and Valerie Hunstock ${ }^{3}$ \\ 1 School of Economics and Management, Beihang University, Beijing 100191, China; \\ chenxdng@buaa.edu.cn (X.C.); niuxin@comac.cc (X.N.) \\ 2 Faculty of Social and Behavioral Sciences, Friedrich-Schiller-Universität Jena, 07743 Jena, Germany; \\ ulrich.hilpert@uni-jena.de \\ 3 School of International Trade and Economics, University of International Business and Economics, \\ Beijing 100029, China; valerie.hunstock@mail.mcgill.ca \\ * Correspondence: reeselee@buaa.edu.cn
}

Received: 13 December 2017; Accepted: 9 February 2018; Published: 12 February 2018

\begin{abstract}
This study proposes and integrates a double lens investigation framework on sustainability and diversities of innovation at the city level in China. Lens I concerns economic performance with the energy intensiveness of the production mode and Lens II involves a four-dimensional model with the current and potential elements of innovation at the city level. Based on 106Chinese cities data, sample cities grouped in Traditional Regions (TRs), Top Economic Regions (TEs) and New Economy Regions (NEs) of the 9 groups are clarified via the Investigation Lens I, with respect to production power, market openness and energy intensive use. The further research findings through the Investigation Lens II show that there are clear connections between innovation and sustainability and such connections are diversified due to economic reasons but also importantly, due to potential factors of human resource and knowledge creation. Cities in TEs group and especially NEs group in China are important on innovation and sustainability while southern cities in China are more innovative, with a higher potentiality of economic growth than cities in northern China. Industrial tradition and business culture can be one of the key factors influencing local innovation and sustainability.
\end{abstract}

Keywords: metropolitan innovation; sustainability; diversities; double lens; regional development

\section{Introduction}

The role of geographically mediated knowledge externality in regional innovation systems has become a hot topic in innovation and policy study journals, with research generally based on typical indicators such as patent records [1]. The geographical location of innovation and knowledge creation is often the topic of major discussion, organized in the 1980's in terms of spatial distribution or concentration [2,3] and the location of high technology industry [4]—particularly the dynamics of regional innovative complexes [5]. These studies reflect the fact that innovation activities are not equally distributed in geographical space; rather, they occur in clusters-especially for high tech content productions (e.g., as in US case [6] or European case by [7,8]).

Meanwhile, geographical location of economic development often raises another hot issue of local sustainability, or rather, ecological concerns, especially when urbanization movement is increasing, such as in China's case $[9,10]$. The uneven distribution of knowledge creation and high-tech production with complex resources or influencing factors can be attributed to difficulties of technology transfer or knowledge sharing among different regions. These kinds of difficulties can be explained by the 
nature of human resources related to the knowledge transfer and spillover across regions [11,12]. The uncertain, non-codified, form of transfer seems to play a role, especially in knowledge intensive sectors; such transfers or spillovers generally cannot be fully explained or by differences in hardware or equipment (in developing country cases), or via even well-established facilities in most emerging economies [13-15]. In terms of necessary facilities for better knowledge transfer or more evenly distributed innovation activities, more rigorous research was conducted to examine the efficiency of the policy oriented efforts on the facilities in at the regional level, or through so called regional innovation systems [16-20]. Among all these studies, metropolitan based innovation studies suggest a new focus on precisely defined regional innovation frames (typically reflected in research by Fischer and others [21]).

On the other hand, sustainability studies also reflect strong concerns on regions and unevenly distributed situations across cities. The important lessons are not yet fully explored in China-related studies of cases of unevenly distributed regional innovation, although there are already studies on a number of topics, such as innovation performance at the provincial level [22,23] and the innovation ranking of typical Chinese cities [24]. Considering the fast pace of industrialization in vast lands in China, together with the rapid growth and penetration of overseas capital from global market, perhaps such city based innovation studies should be extended into diversified nature of cities in different geographical regions in China. Drawing on the variation observed in the previously noted cases, it appears that processes of innovation equally need to be divergent. The situation of metropolises indicates divergences when compared with non-metropolitan situations in China and when Chinese metropolises when compared among each other. Research structures and industrial structures, as well as the agglomeration of highly skilled knowledge workers, equally indicate divergences.

This study makes four contributions to the investigation framework. (1) Double lens investigation framework on diversities of innovation and sustainability, with detailed designed Current performance vs. Potentiality based innovation watch is proposed; (2) Knowledge creation and active communication of human resource are taken into account in this regard; (3) Production side based, with multiple factors on economic and energy intensiveness, which is different from cases in sustainability studies in economic fields; (4) Industrial tradition (again, from production side) and business culture are taken into account, to be combined with economic and innovation indicators, therefore, diversities of innovation and sustainability can be understood from wider scoped perspective. The remainder of the paper is organized as follows: the literature review and research background presents fundamental literature related to metropolitan innovation and sustainability studies as well as research gaps, with an overall picture on China's innovation in regions. In the materials and methods section, a double lens view, a research framework and the influencing factors for a city-based study of innovation and sustainability are analysed. Then, in the empirical investigation section, more detailed cities and metropolitan areas will be investigated through Principle Factor Analysis for diversified dimensions. Conclusions will be provided based on these examinations.

\section{Literature Review and Research Background}

\subsection{The Regional Innovation System}

Until the 1990's, regional innovation phenomena were not regarded as relevant for independent study. Along with the faster pace of globalization and emerging knowledge economy, technology and related knowledge creation has proven important in regions-not merely separate countries. The so-called Regional Innovation System (RIS) has been an important policy and strategic concept since then, even outperforming the national innovation system (NIS) approach. Apparently, any technical innovation needs to be realized firstly in certain geographical regions, with a unique social and cultural background. The RIS study seems more sophisticated than NIS in that it covers diversified resources with multiple layers, being an important complementary part for overall study in the national level, or the industrial level. Cooke did systematic research on RIS with fundamental theories and 
thorough empirical studies. He emphasized the importance of regional connections among production companies, research institutes and higher educational organizations through internal linkages in the region [25]. Nelson extended the research concept and the investigation framework. In China, related studies emerged on the contents, structure and evaluation issues of RIS [26].

In recent years, a tremendous body of referential research on RIS regarding theoretical findings and methodologies has developed. For example, Buesa, Heijs and Baumert study the determinants of regional innovation in Europe through a knowledge production function approach that combines factorial and regression analysis. The dependent variables are patents. While there are initially 21 explanatory variables, these are converted_-by Principle Factor Analysis (PFA) - into five abstracted non-observable "hypothetical" variables reflecting five important aspects of the innovation systems: the national environment, the regional environment, innovating firms, universities and R\&D by public administration. These factors are all significant with respect to innovation activities [27]. Fritsch and Slavtchev [28] find, through their research, that regions dominated by large establishments tend to be less efficient than regions with a lower average establishment size. The more that innovation drives the modernization of industries and the more it attracts both innovative labour and specific enterprises to specific locations, the more it appears that neither one best practice, nor a single path of innovation can be identified: There are rich diversities of innovation opportunities.

Broekel [29] presents an empirical investigation on this issue utilizing conditional efficiency analysis and patent co-application data for the electrics \&electronics industrial sector in 270 German labour market regions. The results show that the relationship between regions' innovation performance and the intensities of regional as well as inter-regional collaboration take the form of an inverted-U shape. Regions with average regional and inter-regional collaboration intensities are found to outperform those characterized by extremely low, high or unbalanced collaboration behaviour.

Based on these important references containing data on regional as well as metropolitan innovation studies, patent statistics appear useful to explain innovation output and for regional comparison. Similar methods are used for examining differences between clusters [30]. However, China related metropolitan innovation studies are limited in detailed differences across typical cities. China has a wider range of geographical (e.g., eastern and coastal regions so close to overseas capital and active market operation and other regions less accessible to overseas market) and economic features (in terms of stronger policy generally in China's inner land and northern China, as opposed to stronger market response, generally in southern China) and it has a significantly more diversified business nature (in terms of industrial tradition and business culture), than is typical in other countries.

\subsection{Cities as Important Elements to Be Studied in Terms of Innovation and Sustainability}

\subsubsection{City as the Centre of a Regional Innovation System}

'City' can be conceptualized in many ways. For example, it might be used, alternately, in a sense as an "urban" entity, a "metropolis", a "megalopolis", an "urban region" and even a "metropolitan region" in order to focus on the characters by size. This implies that, on the one hand, 'city' is considered a geographical concentration when used to explain regional change in economies and in social life and on the other, the larger the territory of the city, the more significant is its impact or determinant function. US based Metropolitan Region studies during 1930-1960 provide standard measures on big cities and their surrounding regions [31]. In China, city-based studies are often conducted on a respective administrative city boundary as defined by government regulations. They focus on only geographically and economically important cities. Xie et al. define a so-called Urban Circle Innovation system and a related evaluation system; their subsequent work suggests that there are spatial structures in such city-based systems of innovation [32,33].

In terms of the character of regional innovation, there are several important issues explored in a number of pioneering studies, primarily of the networking relationship among cities. For example, Cooke [34] studied German high-tech industries in geographical areas, focusing on local networking 
effects. He proved, empirically, that intra-region interactions among different entities would positively function as an enabling factor on local high tech industrial development. In fact, a number of important function network factors to be integrated into the characterization of city-based innovation, can include the quality of labour in the network and a labour market nearby, as well as network agglomeration of industrial enterprises and relevant universities, as suggested in Hilpert and Smith [35]. In China, during the comparatively early years of the implementation of the Opening-Up Policy, networking among smaller firms proved to be highly important. It remains as one of unique factors in regional economic development. Typical studies by geographical economy scholars [36,37] during that time emphasized more stable networking relationships in the region for better innovation output, often via the networking of local industrial firms, local governments with some local institutes and local individuals. They were all considered important players in regional innovation at a city or even town level. And seen from a regional innovation research perspective, they could be considered an agglomeration of numbers of nearby towns. The following factors may prove crucial in city-based regional innovation studies: Knowledge clustering. Cities may be a useful locus for examining knowledge-clustering phenomena. Jaffe [38], by adopting patent information from respective industrial fields, showed that local patents in different states in the US were highly related to university R\&D expenditures in the corresponding regions, which again implied a regional boundary of knowledge clustering.

Knowledge transfer distance and boundary of metropolitan areas. Since it is clear that knowledge transfer is rather clustered in geographic regions, as it shows in numbers of international studies mentioned before, it is reasonable to expect that city-based innovation is bounded in technologies and related engineering techniques (or tacit part of knowledge). Griliches [39] suggested three kinds of distance in terms of knowledge spill over: market distance (in the sense of value chain), technology distance (in the sense of distance between companies) and geographical distance, indicating that technology or knowledge spill over decreases along with geographical distance increases. Geographical closeness is always a key factor in knowledge clustering and transfer [40,41] and thus metropolitan areas may serve as a better research focus with respect to regional innovation activities.

\subsubsection{Regional Based Sustainability Studies}

Most studies involved in sustainability study would focus typically on three (economic, social and environmental dimension) or four dimension models, such as Prism model developed by Spangenberg [42], on economic capital (financial capital, or called man made capital), social capital, human capital and natural resource capital [43]. In fact, such primarily two side view (sphere of human domination, or economic motive, vs. sphere of natural regulation, or sustainability motive) reflect only statistic situation, while from innovation perspective, the two side might be rather combined. The human capital and capital goods are two typical innovation or technology based resources, with former one as dynamic or enabling and latter one as codified resources.

Research by Feng and Chen [44] show that environmental regulation and green innovation are equally important and the innovation may prove even more important, as it is more active and responsive to the regulation policies.

However, the clear link between innovation and sustainability has not be explored in more detail, although in both theoretical and in practical, innovation activities, especially knowledge based newly developed technologies should go in parallel with increasingly demand on greener economies and quality of economic development. This paper focuses on city level innovation, together with typical indicators on industrial production based character which links to sustainability issues, in such a way, we connect innovation study with sustainability nature on more detailed city level.

\subsubsection{China Related Metropolitan Innovation and Sustainability Overview}

Regarding China related studies, there are numbers of typical findings on regional innovation as well as in sustainable development. Regarding to innovation characters in regions, Johnson and 
Liu [45] empirically explore the connections among regional patenting behaviour, technology markets and the number of technology firms across 30 regions of mainland China. The results suggest that technology markets are a useful linkage to connect patents and active technology oriented business across regions. Such activities involve allocating patented technologies from regions they were created and transferring them to region in which they are used. This is timely driven dynamic movement, given the nascent understanding of technology markets in China and the country's drive towards promoting indigenous innovation.

Via a stochastic frontier model, an increasing disparity in innovation performance among Chinese regions can be found [46]. The estimated results show that government support, the constitution of the R\&D performers and the regional industry-specific innovation environment are significant determinants of innovation efficiency [47]. This shift underlies the widening gap in regional innovation performance. It needs to be noted that policy strength is often stronger in two aspects in comparative sense: namely, basic and applied research related (with corresponding representative institutions/universities), state-owned enterprises (with corresponding heavily concentrated industries and metropolitan areas) this provides the basis for the emerging diversities of innovation. Such regional variations in interactions and function of different actors may create different opportunities for innovation and a city's concentration will determine the metropolitan context. Such processes provide the basis for the geography of innovation divergences and sustainable development nature to be identified today.

There are numbers of signs on sustainability concerns on Chinese related innovation studies, for example, more dynamic investigation on diverse innovation can be found in regional and sustainability journals may indicate such concerns, such as, regional enabling factors for better driving force on local economies are stressed on innovation in geographical journal [48], and active evolution based innovation on Chinese regions with diverse situation and with convergence trend across regions in sustainable study circle $[49,50]$. On the other hand, more direct link of innovation study with sustainability concerns can also be found, e.g., from Yu et al. [51], which explore function of knowledge creation upon sustainability over specific region in China. Their conclusion divides such influence on the two parts, direct impact on sustainability and indirect impact via sustainable competitive advantage, which again, emphasizes importance of dynamic influence, rather than more stable ones on the sustainability.

\subsection{Overall Picture on China's Innovation in Regions: Which Kinds of Factors Are Important?}

Based on previous discussion, our study provides a contrast figure as follows, between economic performance and other typical resource, as well as other indicator to link sustainability. In this chart, four kinds of data are shown together, including economic development in the region (local production output), economic openness to market (Foreign Direct Investment, FDI) and social factors (population) across 106 cities in China.

The following chart provides for a comparison of such diversities (Figure 1), where the first letter $\mathrm{N}$ denotes north China and $\mathrm{S}$ denotes south China; the 2nd letter $\mathrm{C}$ denotes coastal China and $\mathrm{N}$ denotes non-coastal China. The 106 important sample cities are ranked by production output, in contrast with other typical indicators. It can be seen from Figure 1 that even economic and openness measures diverse each other and innovation capacity as well as population measure vary in a great deal with economic output, especially for those samples within top $50 \mathrm{~s}$. It is true that regions, especially cities, are actually differentiated in economic and other knowledge and innovation based factors. This may imply, on the one hand, that innovation movement is moving individually, when economic performance reaches to a certain standard. Besides, due to the nature of specific sectors (which vary in terms of demand in techno-scientific linkages and in closeness with other players for industrial development), large differences among cities or metropolises can exist depending on their industrial composition. Also, other multiple and diversified factors are noteworthy and ought to be studied in city-based regional innovation investigations, especially when sustainability issue is taken into account. 
What is more important is that this strongly signify the emergence of diversities which should be unavoidable in city based characters and worth to be further studied, especially in case of fast growing Chinese economies. The detailed information for Figure 1 including 106 cities is listed in Table A1 in the Appendix A.

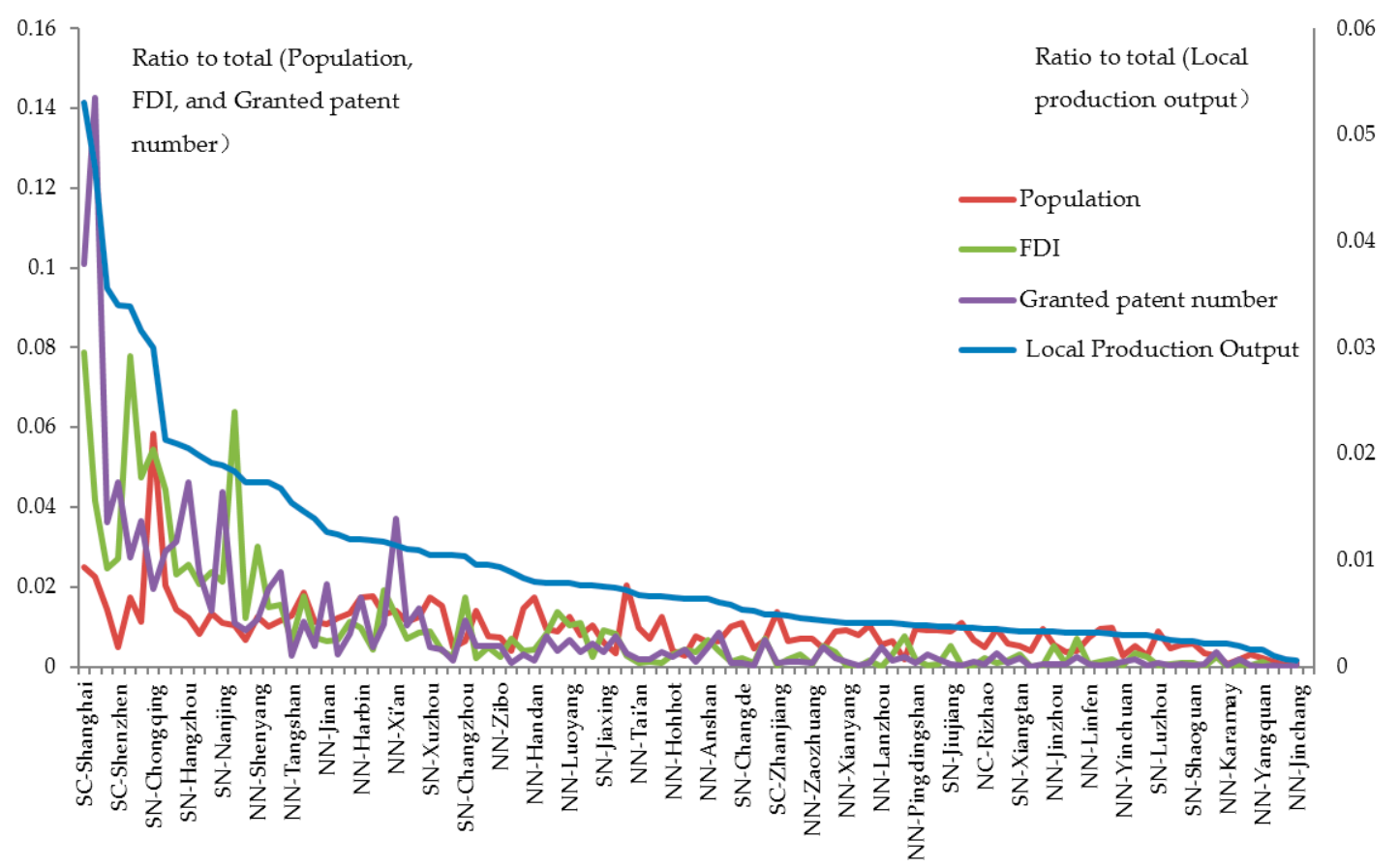

Figure 1. Comparative indicators on local production output (ranking indicator), Foreign Direct Investment (FDI), Granted patents and Population. The graph represents only 36 out of the 106 cities.

Based on previous literature analysis and Chinese economic context for innovation and sustainability studies, gaps and research issues can still be found in the following:

1. Major concerns on regional innovation (particularly city based) are more focused on uniforms of innovation pattern, or similarities, rather than diversities of innovation, or dissimilarities, together with their development background;

2. Major concerns on sustainability study are more focused on overall macro level statues, such as natural resource, social capital, as well as human resource or human capital as rather abstract measures, rather than more detailed micro level investigations toward city level innovation activities in production side;

3. More importantly, major concerns on sustainability studies are rather separated from knowledge creation and dynamic innovation movement, although such link does exist and should be highly relevant. Studies including such link (as research by Yu, et al. [51]) are using less direct information on city based economic and innovation.

This research is aimed to bridge such gap by adopting first hand data from city level and combining economic, knowledge creation, industrial innovation and efficiency indicators together, with particular focus on sustainability related measures (by emphasizing production and R\&D efficiency and possible roles of human resource as indications of potentiality, together with business and industrial tradition measures as contrasted features) in the region. In this way, this study will provide another wider scoped window on diversified innovation and sustainability in typical city level with China's economic context, the largest emerging economy in the world. 


\section{Materials and Methods}

Based on our literature review on regional innovation and sustainability, it seems that there are two basic angles for studying metropolitan innovation and sustainability, particularly from production side. One is the Production mode, or sustainability related production, which is usually related to both economic performance and energy efficiency; The other is the Innovation mode, or Current vs. Potential level of the economic development in quality measures, or put it more precisely, current technology innovation (current input and output based) and potential innovation (knowledge creation and dynamic nature of human resource).

Therefore, in this study, we adopt a two lens-view of metropolitan innovation and sustainability. Lens I investigates economic development and energy efficiency. Lens II investigates through an interconnected framework on current vs. Potential nature of innovation mode.

\subsection{Lens I: An Investigation Framework on Economic Development and Energy Intensiveness}

An investigation framework on economic and energy efficiency can be designed in Figure 2. While economic performance may indicate the brightest side of a particular city, energy cost and efficiency, measured by the ways of energy cost volume and unit production for the economies in the region show some other side. Therefore, the following 2 plus 2 dimensions may capture energy use based city characters on their economic performance. It should be noted that for energy cost measure, there are still different mode for higher efficiency and lower efficiency in energy use, which may involve in innovation consideration in the following section.

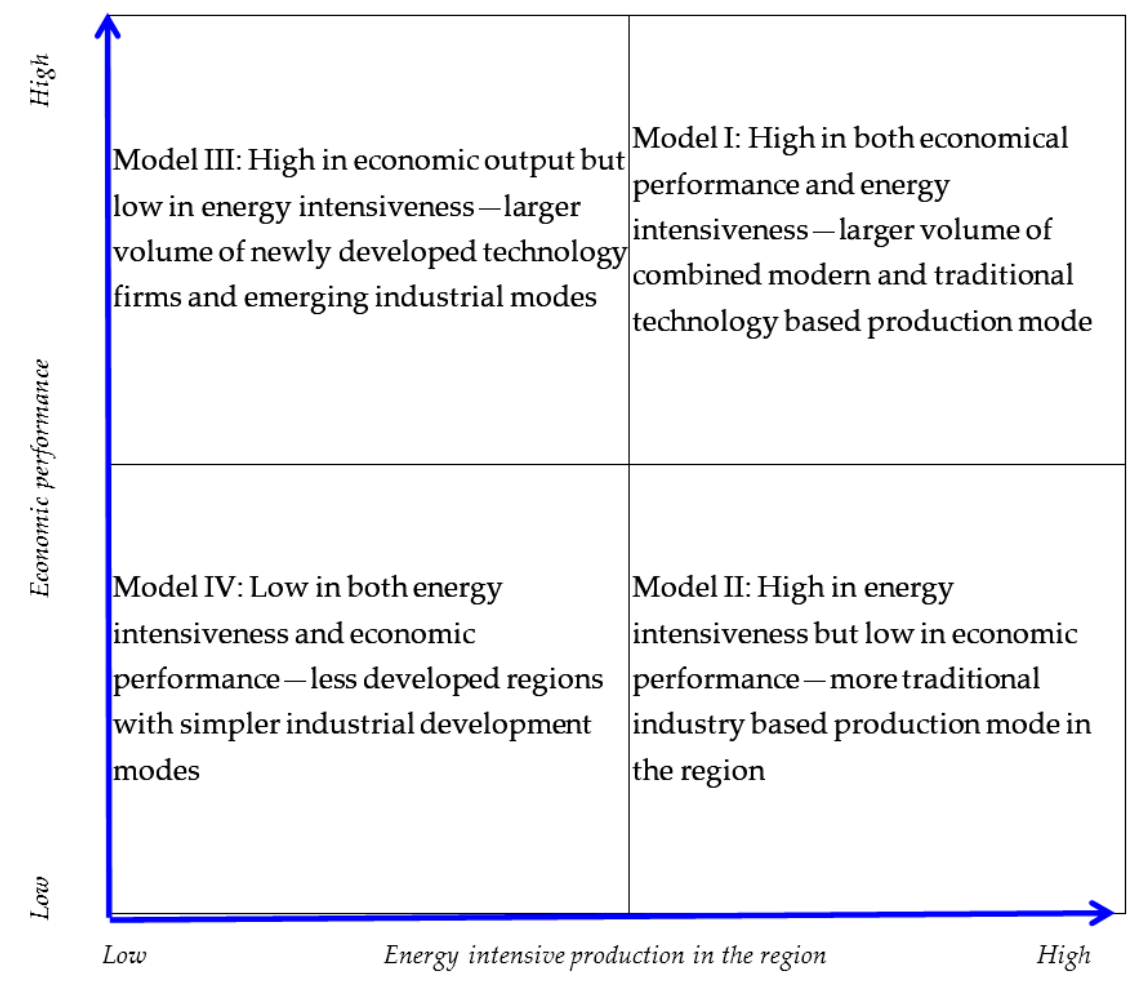

Figure 2. Investigation lens for regional production modes: economic performance vs. energy intensiveness.

\subsection{Lens II: An Investigation Framework on Mode of Innovation-Current vs. Potential Characters}

We define metropolitan innovation investigation framework, primarily an interconnected framework for detailed selection of relevant indicators, with major focus on current (both economic and innovation based) and future (potentiality) dimensions (knowledge creation based), also with combination of energy intensiveness and industrial tradition as necessary economic character in the region, which is important to portrait the sustainability nature of the corresponding cities. 
Relevant data can be collected in Chinese case in particular and different diversified economic development pattern can then be found, with the application of Principle Factor Analysis (PFA) to the data processing, in order to abstract reasonable performance dimensions on such innovation and sustainable development pattern. To collect data on relevant indicators, the following four kinds of principles are provided, also based on the literature analysis in the previous section.

\subsubsection{Current Economic and Innovation—Relative Measures}

This may generally involve input, output and process measures on current production capacity supported by necessary innovation strength in the region. Input measures include not only financially relevant measures, such as $R \& D$ or $S \& T$ expenditures and investment volume to reflect quality expectations on economic progress in the region but also density of industrial firms, since such concentration of business firms and investment can be active indicators for local regions. Also included are overseas investments as an indicator of both market expectation and market openness at the same time. Since there can be larger variance among different metropolitan areas in China in terms of economic and innovation performance, relative measures (either relative to local indicators or to overall total among all investigated areas) are more reasonable to compare efficiency or capacity of economic innovation.

\subsubsection{Potential Economic Development Impact of Human Resource and Knowledge Creation Capacity}

Human Resource and Knowledge Creation dimension will clearly address potentiality for future quality backed economic development and thus can be more directly related to sustainability. It should be noted that there are different levels of measures on human resource and knowledge creation. For example, besides accumulated human resources in certain regions, dynamic movement of human resources may prove to be much more important indicators to contrast human flows (as temporary immigrants) and also knowledge flows among particular cities, such as Hilpert and Smith [35] discussed in biotechnology related analysis on function of human resource movement.

Based on previous literature, stable accumulated and dynamic natures of local human resource and related knowledge creation may be reflected by following typical measures:

Population-related measures to reflect size of potential human resource.

Knowledge-based human resources, such as the R\&D or engineering workforce, or more knowledge-creating human resources as educational institutions.

Volume or density of communications by population, which can indicate demand degree or frequency of information exchange by the population in the region.

Networking linkages among individuals involved, or between institutions. This can be reflected in formal collaboration deals or frequent linkages among a population or organizations in the region, however, in more solid collaboration sense, usually with targeted missions.

Information exchange via communication channels, usually including random and more free sense communication (in comparison of networking linkages, in which collaboration is already formed), as such activities can often be a better vehicle to transfer information and knowledge and possibly generate new ideas. Indicators implying cross-city information exchange or networking can be always considered important variables to city based innovation movement.

\subsubsection{Efficiency and Other Enabling Factors}

Efficiency measures are also considered in this study. Unit production of innovation output, such as patents, can be used to compare productive innovation among sample regions and to imply procedures of innovation, as efficiency is always the result of process innovation or management based organizational innovation. Indicators of efficiency levels and of changes to these levels should be qualified for explaining to a certain extent regional innovation. Similarly, density of input, or unit-input 
(in relative sense) measures can also be used to compare sample regions on their input strength during the process.

However, if considering differences between investment on tangibles and intangibles, there should be two kinds of efficiency measures, namely tangible-related and intangible-related efficiency measures, typically:

For tangibles, typical measures include, efficiency on equipment or hardware based output; efficiency on production organization (for example, per enterprise related measures) based output. And for intangibles, typical measures include efficiency on R\&D output measures; efficiency on research output per science and technology/R\&D personnel; efficiency on unit human resource output, etc. These efficiency-based indicators may also imply differences among regions in features of local production and possibly in the nature of local innovation.

\subsubsection{Influence of Industrial Traditions}

Industrial traditions in the region or city are commonly considered important influencing factors on innovation. How to capture a cultural essence in innovation research, however, is highly challenging. We would consider that in industrial development, historical-industrial heritage or tradition and geographically-based business characteristics of local peoples, etc., might be better suited to address the local industrial traditions. In fact, industrial traditions (engineering and operation culture) and policies (governance culture) in China can be important factors to explain evolution in development of heavy industries in different regions during the early 1950's and 1960's [52] and development of ICT-related industries in diversified regions since 1990's [53]. It is obvious that industrial traditions and business culture, together with dynamic changes in available resources and markets, can surely make an important impact on regional differences, particularly on sustainability level. Therefore, dimension of past, or historical accumulation, including industrial tradition and business routines alike, can be used for cultural based study. Such situations indicate that processes of innovation are influenced by many different factors and that effective innovation may arise from precisely these diverse opportunities. Traditions, cultures and businesses may constitute such divergent situations and may contribute towards individual developments.

More precisely, this study compares some traditional features of sample cities, for example, heavy industry (usually capital-intensive and upper-stream sectors, such as iron \& steel, petro-chemical and heavy mechanic sectors and alike.)regions should be very different from Light industrial cities (such as traditional home appliance), In any case, traditional routines, embedded in its manufacturing manner, can be one of the important factors to represent local industrial cultural, along with those purely economic indicators.

It should be noted that sustainability nature of the sample cities can be reflect through all four kinds of characters, however, with different correspondence. While Current Economic and Innovation-related dimension is clearly economic performance based (even input on innovation may still economic power based).

\subsection{Research Framework}

By considering the factors mentioned above and their influence on each other, the following research framework, composed of the four elements in this study, is proposed to cover a broader range of interacting factors than merely economic and innovation performance. The most important feature of this framework is that human resource capacity and knowledge potential (e.g., human resource input for science and technology research, the value of temporary immigrants for knowledge sharing and information/communication density) are included. The potential power of local human resources can also be reflected in higher level of value creation per unit fixed asset measure. There should also be elements to compare what occurs now with what might occur in the future (i.e., to mark innovation potential). Therefore, the four elements here are marked 'current' and 'potential'. Moreover, 
efficiency-related measures are also included in order to catch characteristic features of local industries, which again may be connected to particular local industrial culture (history) and current practices.

In the above chart (Figure 3), four kinds of factors are clustered with different representative groupsof available indicators to show the state of current economic development in the region and state of potential capacity for the future (indicated by industrial innovation and human resources as well as related knowledge creation and information transfer, given the fact that human capital and knowledge assets are key resources for innovation and for related industries in the near future). The following empirical studies will be conducted according to this framework over typical sample cities in China.

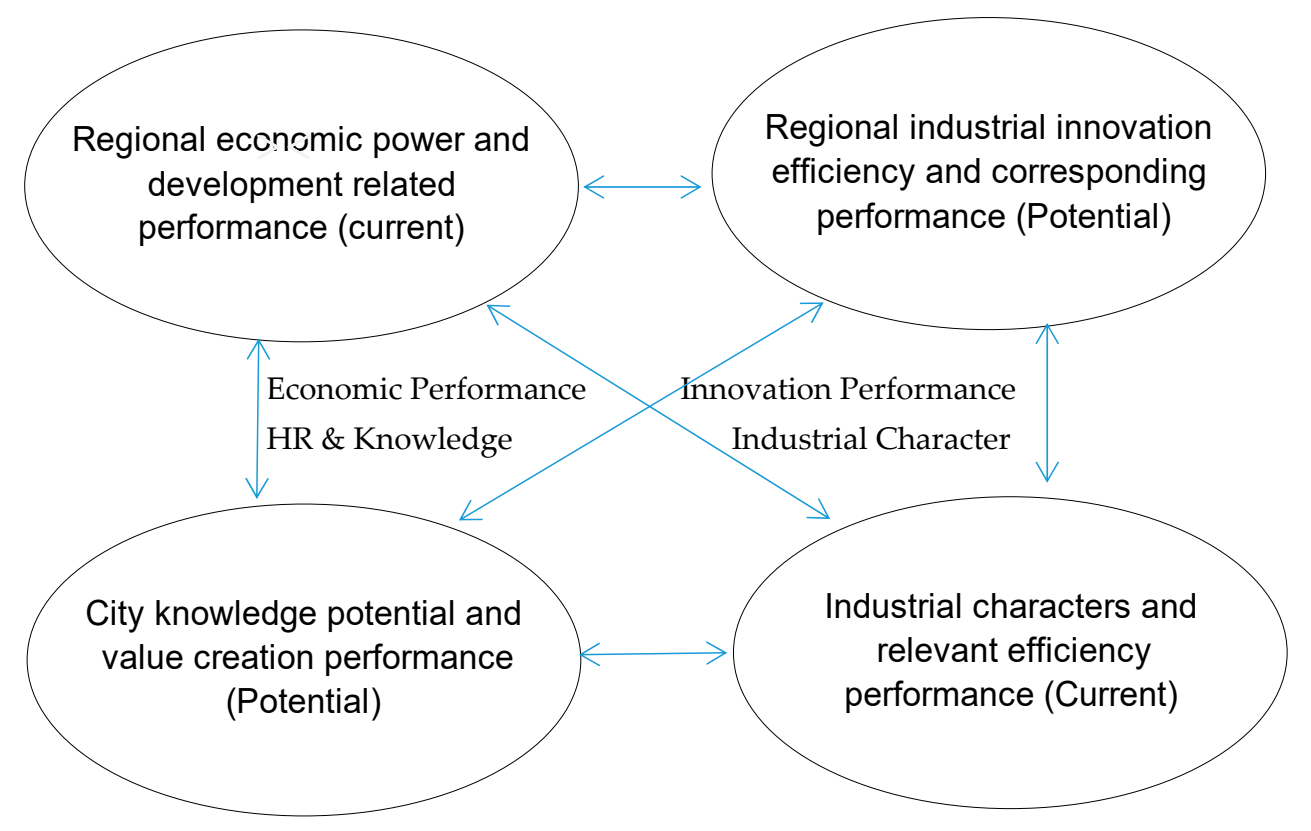

Figure 3. Investigation framework on metropolitan-based innovation movement. Regional economic and industrial performance (current linkage) vs. city HR \& knowledge and industrial innovation performance (potential linkage).

\subsection{Methodology Strategies}

This article adopts the following method strategies on data collection and processing:

1. Based on the above literature review, three kinds of indicators are collected in this study (refer to Table 1), which include accessible data resources.

2. Important principles are considered for further processing the related data from those accessible data resources, namely, (1) Principle of contents: Indicators should clearly reflect research demand on the nature of the variables described in Sections 3.2.1-3.2.4; (2) Principle of comparability: indicators should be comparable among chosen sample cities, therefore, only relative values of indicators, e.g., proportion of indicators, are used; (3) Principle of availability: data should be available for the designed dimensions (for example, regarding to Efficiency on R\&D activities, since patent data and number of science \& technological personnel are available in statistical yearbooks in China, we use Granted Patents Per S\&T Personnel).

3. Principle Factor Analysis technique is applied to this study (based on SPSS 20.0). This kind of technique can best abstract the most representative indicators among all selected ones, effectively decreasing numbers of investigating dimensions. The major character of such technique is to capture the information of those indicators with the highest level of differences among samples, as factor 1 and indicators with next higher level of differences, as factor 2 and so on. In this way, fewer factors can successfully replace original multiple indicators, while still maintaining original 
information on differences of original indicators among samples and achieving reasonable dimension reduction. The newly formed factors can be further defined according to those original indicators with higher correlations with those factors. When factors are generated from such data processing, nature of samples can be found according to scores of related sample on each corresponding factors. Such techniques can be best fitted to the research purpose in this study, abstracting meaningful factors on innovation and sustainability, from original indicators and positioning those sample cities according to their values on each of the abstracted factors.

Table 1. Selected indicators on city based nature of innovation and sustainability.

\begin{tabular}{lll}
\hline & & FDI volume in the region \\
$\begin{array}{l}\text { Regional Economic } \\
\text { Power Concerns }\end{array}$ & $\begin{array}{l}\text { Regional Market } \\
\text { concentration and } \\
\text { production power }\end{array}$ & $\begin{array}{l}\text { Overseas investment } \\
\text { Industrial firms } \\
\text { Regional production value } \\
\text { Transportation } \\
\text { Internet connection }\end{array}$ \\
\hline \multirow{2}{*}{$\begin{array}{l}\text { Regional Innovation } \\
\text { Concerns }\end{array}$} & Innovation (Input) & $\begin{array}{l}\text { Regional science and technology expenditure } \\
\text { Regional educational expenditure }\end{array}$ \\
\cline { 2 - 3 } & Innovation (output) & $\begin{array}{l}\text { Patenting volume } \\
\text { Granted patents }\end{array}$ \\
\hline \multirow{2}{*}{$\begin{array}{l}\text { Regional Environmental } \\
\text { Concerns }\end{array}$} & $\begin{array}{l}\text { Environmental friendly } \\
\text { production }\end{array}$ & $\begin{array}{l}\text { Green resources } \\
\text { Energy intensiveness energy } \\
\text { Water supply }\end{array}$ \\
\hline
\end{tabular}

\section{Data and Results}

According to previous discussion and proposed investigation frameworks, following indicators are considered as typical dimensions of the investigation on innovation and sustainability among sample cities in China.

We then collect necessary data to reflect those variables on relevant two kinds of lens and four dimensions. Sample cities are collected according to economic performance, e.g., only those cities with certain level of local production value can be selected and 106 sample cities are finally selected for this study, based on their larger economic statues. Other relevant economic and social indicators are then collected from those sample cities, primarily from various kinds of statistical yearbook (mostly from $<$ China City Statistical Yearbook $>$ in 2013), particularly, innovation data are collected from other sources, e.g., patent data from SIPO website in China.

\subsection{Investigation through Lens I}

The following table (Table 2) is provided to clarify differences of those grouped sample cities, with detailed description of those sample cities in each of the groups, under the Lens I investigation framework. In fact, this table provides a picture of the Diversities of Economies and Sustainability in energy use, among the sample cities.

Three kinds of indicators from the yearly statistical book on cities are used to group sample cities in this study, namely Production Value (Indicator for economic power), Overseas Capital Ratio (Indicator for Market Openness) and Electricity Cost Per Firm (indicator for energy basedproduction mode). Detailed rules for the classification and related groups with their marks are shown in Table 2 . * Notice: EcoTp 60/Open Tp 60 or other figures indicate those samples at positions lower than 15 but higher and include 60 or related number. ${ }^{* *} \mathrm{~S}$ stands for sample cities in southern China, while $\mathrm{N}$ stands for sample cities in northern China. In this case, numbers of sample cities are listed and contrasted between south and north in each of the groups for further reference. ${ }^{* * *}$ Notice: Since there is no sample city in both Top 21 group in energy cost and Top 15 in economic power, the energy cost rank is extended to Top50 in TE2. 
Special names in this table are used to classify different city groups. Sample cities in Group NE1 (New Economy Region 1) are significant in both economic performance and energy efficiency, which implies that those cities are running in a newly developed manner of economic progress, either high-tech based or service industry oriented. In any case, Newly Emerging can be named for those samples in the group. Similarly, sample cities in NE2 (New Economy Region 2) might be considered also significant in energy efficiency but with less economic power compared with samples in NE1. On the contrary, sample cities in TR1 (Traditional Economy Region 1) can be considered lower economic capacity but with much higher energy cost, which implies traditional industrial regions. Similarly, samples in TR2 (Traditional Economy Region 2) can be considered as more capable in production but require higher levels of energy use. It should be noted that samples in TE2 (Top Economy Regions 2) are both highly capable in economic production and significant openness and also have a higher level of energy cost, which indicates that those relevant sample cities may be in key positions in different manufacturing sectors, or Top Economies. Meanwhile, samples in TE1 (Top Economy Regions 1) can be economically capable of production value and less energy cost at the same time, which implies new type of production or a technology-intensive nature. Finally, remote regions can be defined here as sample cities that are in lower economic positions and have lower energy cost. Samples in RM2 (Remote Economic Regions 2) are classified due to their higher energy input but still lower production output.

It is clear that in this section, sustainability is the major concern, the top figure such as number 1 is always given to the region with lower energy cost or higher energy efficiency by unit production. In this way, a more diversified characters of those sample cities can be grouped and contrasted in terms of newly emerging industrial cities with higher efficient in energy cost (NEs), key industrial cities with top economic power and energy cost (TEs), traditional industrial cities with comparatively lower economic output and highest energy cost (TRs), more "remote" cities with comparatively lower energy cost but also lower economic output (RMs) and cities with medium level of both economic output and energy cost (Ms, Medium Economic Regions). Consequently, among these divergences of innovation, the context of a particular process may make a significant difference.

Table 2. Classification of the sample cities in this study to indicate diversities of economies.

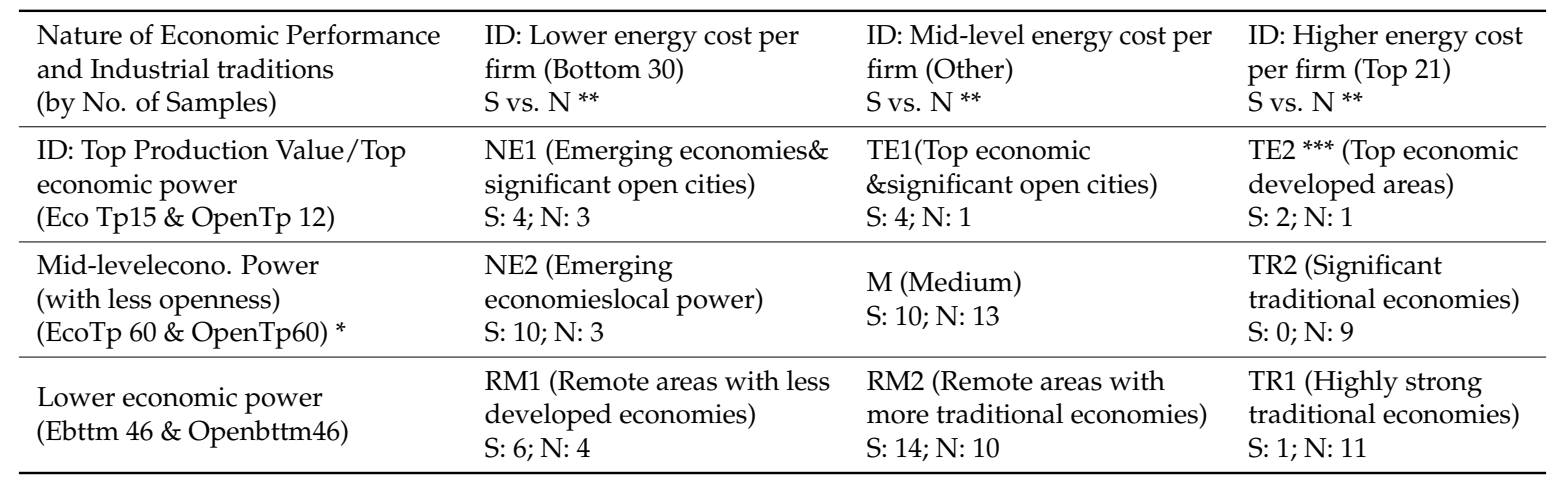

Moreover, considering larger differences in terms of economic performance and innovation between inner land cities and coastal cities in China and differences in business culture between south and north in China, geographical differences are specially clarified among all sample cities in this study in order to look into diversities of sustainability and diversities of innovation along these two dimensions. It is obvious that in Table 1, while sample southern cities in NE2 and TE1 more significantly outperform in number, than northern cities, northern samples in TR1 and TR2 are much larger in number of cities than southern. This implies a meaningful classification for their production nature, especially in terms of industrial culture. When such divergent variables meet in a particular situation, they may not only generate important diversities but also create different nature and modes of innovations. 


\subsection{Investigation through Lens II}

Data on 14 different indicators (as seen in Table 3) are used in this study, based on the discussion in previous section. We also testified corresponding indicators, for example, 14 indicators are finally selected from original 16 indicators (being available for this study), through experiment in order to remove redundant ones (with higher level of correlation) and to use more representative indicators. The detailed descriptive statistics and definitions of indicators are listed in Table 3, which corresponds with the designed four-dimension investigation framework.

Conditions of data from selected indicators for further processing are satisfied: the Kaiser-MeyerOlkin (KMO) statistics of the sample data is $0.765(>0.7)$ and the Bartlett test is significant at $p<0.01$, indicating that the data is amenable for factor analysis. After carefully processing the sample data via the Principle Factor Analysis, exactly four factors with an eigenvalue larger than 1.0 are extracted based on the Kaiser Criterion, representing $83.45 \%$ of original information from those indicators (Table 4 ).

In Table 4, the precise loading of each indicator on the corresponding extracted factors is provided. A loading indicates the degree of correlation of a given variable with a particular factor, while a score represents the performance of a given metropolitan economy on a particular factor. It can be seen that, all indicators load high $(>0.65)$ on their expected factors but basically load low $(<0.4)$ on other factors, which extract most part of the information from those relevant indicators. The correlation matrix is shown in Table 5.

Table 3. Descriptive statistics and definitions of sample indicators.

\begin{tabular}{|c|c|c|c|c|}
\hline Indicator & Mean & S.D. & Definition & Factors \\
\hline RFD & 0.98 & 1.58 & $\begin{array}{l}\text { Ratio of FDI volume in the region } \\
\text { (\% of all sample cities) }\end{array}$ & \multirow{5}{*}{$\begin{array}{l}\text { Factor } 1 \text { (Current performance) } \\
\text { Metropolitan economic power and } \\
\text { innovation output related } \\
\text { performance (simplified as MEIO) }\end{array}$} \\
\hline RPG & 1 & 2.03 & $\begin{array}{l}\text { Granted patent volume } \\
\text { (Ratio to average all sample cities) }\end{array}$ & \\
\hline FDF & 0.04 & 0.03 & $\begin{array}{l}\text { Overseas investment-ratio to local fixed asset } \\
\text { investment }(\%)\end{array}$ & \\
\hline RGA & 1 & 1.68 & $\begin{array}{l}\text { Green land ratio of the sample city } \\
\text { (\% of all sample cities) }\end{array}$ & \\
\hline RIQ & 1 & 1.03 & $\begin{array}{l}\text { Numbers of industrial firms } \\
\text { (Ratio to average of all sample cities) }\end{array}$ & \\
\hline PSA & 0.73 & 1.39 & $\begin{array}{l}\text { Patenting volume per science and technology } \\
\text { personnel }\end{array}$ & \multirow{3}{*}{$\begin{array}{l}\text { Factor } 2 \text { (Potential capacity) } \\
\text { Metropolitan industrial innovation } \\
\text { efficiency and corresponding } \\
\text { performance (simplified as MIIC) }\end{array}$} \\
\hline PSG & 0.04 & 0.05 & Granted patents per S\&T personnel & \\
\hline HSE & 893.2 & 1057.3 & $\begin{array}{l}\text { Science and technology expenditure per } 100 \\
\text { S\&T personnel }\end{array}$ & \\
\hline HPC & 4292.7 & 7127.2 & Transporting passengers per 100 local residents & \multirow{4}{*}{$\begin{array}{l}\text { Factor } 3 \text { (Potential capacity) } \\
\text { Metropolitan human resource and } \\
\text { dynamic exchange capacity and } \\
\text { relevant performance (simplified } \\
\text { as MHRD) }\end{array}$} \\
\hline HIE & 21.54 & 16.3 & Internet connection number per 100 population & \\
\hline HEE & $162,208.7$ & 108,091 & Educational expenditure per 100 population & \\
\hline UFG & 1.7 & 0.67 & Regional production value per unit fixed assets & \\
\hline PEP & 967.6 & 1172.9 & $\begin{array}{l}\text { Electrical energy (KW hour electricity) cost per } \\
\text { enterprise in the city }\end{array}$ & \multirow{2}{*}{$\begin{array}{l}\text { Factor } 4 \text { (Current performance) } \\
\text { Metropolitan industrial nature and } \\
\text { efficiency performance (MINE) }\end{array}$} \\
\hline UWI & 0.03 & 0.02 & $\begin{array}{l}\text { Water supply cost per production output in } \\
\text { relevant city }\end{array}$ & \\
\hline
\end{tabular}

From the results of the analysis, it can be seen that value of Factor 1 (simplified as F1) clearly represents current economic and innovation level of performance(such as granted patent ratio to all sample cities) in the corresponding cities, while values of Factor 2 and Factor 3 (simplified as F2 and F3, respectively) can be used as potential performance, since F2 is more industrial innovation efficiency related (e.g., patenting quantity per R\&D person) and F3 is clearly a more dynamic human resource movement and information intensive relevant measure. Value of Factor 4 (simplified as F4) indicates more on industrial nature of the investigated cities, however, the indicator relevant to this factor is the 
type of energy intensive, thus, cities with higher value on this factor should be considered as more heavy industry related or more traditional industry related and less effective under current industrial output pattern.

Table 4. The factor loading of each indicator on the principle factor.

\begin{tabular}{ccccc}
\hline Indicators & Factor $\mathbf{1}$ & Factor $\mathbf{2}$ & Factor 3 & Factor 4 \\
\hline RFD & 0.926 & 0.176 & 0.051 & -0.052 \\
RPG & 0.813 & 0.002 & 0.287 & -0.047 \\
FDF & 0.746 & 0.269 & 0.332 & -0.081 \\
RGA & 0.714 & -0.116 & 0.479 & -0.022 \\
RIQ & 0.654 & 0.562 & 0.236 & -0.220 \\
PSA & 0.053 & 0.958 & 0.093 & -0.071 \\
HSE & 0.094 & 0.940 & 0.153 & -0.041 \\
PSG & 0.153 & 0.943 & 0.146 & -0.079 \\
HPC & 0.058 & 0.101 & 0.888 & -0.087 \\
HEE & 0.414 & 0.143 & 0.797 & 0.155 \\
UFG & 0.257 & 0.149 & 0.779 & 0.007 \\
HIE & 0.290 & 0.169 & 0.808 & 0.021 \\
PEP & -0.094 & -0.117 & 0.049 & 0.939 \\
UWI & -0.062 & -0.060 & -0.016 & 0.930 \\
Cumulative variance after rotation $(\%)$ & 24.178 & 47.205 & 70.193 & 83.420 \\
\hline
\end{tabular}

Extracted method: PFA. Rotation: Kaiser standardized orthogonal method (Varimax).

Regarding the real position of the sample cities on those F1 through F4 dimensions, a further classification among all sample cities is conducted according to their economic performance (industrial production value), economic openness or market mechanisms (measured by overseas capital ratio) and industrial tradition (measured by energy cost).

According to the above-defined rules, 106 sample cities are grouped in 9 divisions in Table 2. The respective numbers of sample cities are also provided in order to provide a general picture on economic sides of diversities among those sample cities in relevant locations. The following charts are then provided according to the factor scores of PFA to contrast sample cities firstly with current economic and innovation capacity (F1) and potentiality with industrial innovation performance (F2) in Figure 4, as well as potentiality with human resource and knowledge creation performance (F3) in Figure 5. Since geographical locations are especially salient for this study (and which we also believe very much relevant to study diversities of innovation in China, particularly in terms differences between inner land and coastal and between Southern and Northern China), over distributions of those 9 groups of samples, these respective figures (Figures 4-6) are designed to contrast sample cities along with these dimensions and divisions.

It is obvious from Figure 4 that coastal cities appear to be more significant along the dimension of industrial innovation capacity (F2), while samples in similar group are much more diversified on the dimension of market development and absolute advantage in patent volume (F1). In fact, typical big cities, such as the big three cities (Beijing, Shanghai, Tianjin, all marked with TE1 and TE2), are usually ranked top in F1 (the current economic and innovation output). While Shanghai (marked with TE1) is ranked top in F1, Suzhou (near Shanghai, marked with NE1) is the highest on F2. However, there are other NE1's and NE2's, as well as TE1's and TE2's scattered along dimension of F1. However, it should be noted that typical sample cities around Shanghai, or in Yangtze Delta region, are in the top cluster along dimension of F2, or industrial innovation capacity measures.

Figure 6 provides another map, with exactly the same locations of the sample cities, except that they are divided into Southern and Northern cities. Then it is more obvious than in Figure 5 that southern cities are in higher position in terms of industrial innovation capacity (F2), than inner land-coastal cities are. In this case, we use South vs. North dimension for rest of the figures over the sample cities in the 9 groups. 
Table 5. The correlation matrix of the sample data in this study $(\mathrm{N}=106)$.

\begin{tabular}{|c|c|c|c|c|c|c|c|c|c|c|c|c|c|c|}
\hline & RFD & RPG & FDF & RGA & RIQ & PSA & PSG & HSE & HPC & HIE & HEE & UFG & PEP & UWI \\
\hline RFD & 1 & $0.680^{* *}$ & $0.806^{* *}$ & $0.596^{* *}$ & $0.710^{* *}$ & $0.215^{*}$ & $0.294^{* *}$ & $0.265^{* *}$ & 0.187 & $0.317^{* *}$ & $0.485^{* *}$ & $0.266^{* *}$ & -0.145 & -0.13 \\
\hline RPG & & 1 & $0.577^{* *}$ & $0.707^{* *}$ & $0.571^{* *}$ & 0.112 & $0.215^{*}$ & 0.121 & $0.288^{* *}$ & $0.443^{* *}$ & $0.569^{* *}$ & $0.442^{* *}$ & -0.112 & -0.103 \\
\hline FDF & & & 1 & $0.556^{* *}$ & 0.679 ** & $0.304^{* *}$ & $0.399 * *$ & $0.372 * *$ & $0.446^{* *}$ & $0.524 * *$ & $0.604^{* *}$ & $0.437^{* *}$ & -0.177 & -0.122 \\
\hline RGA & & & & 1 & $0.514^{* *}$ & 0.003 & 0.106 & 0.055 & $0.397^{* *}$ & $0.585^{* *}$ & $0.569^{* *}$ & $0.576^{* *}$ & -0.048 & -0.061 \\
\hline RIQ & & & & & 1 & $0.593^{* *}$ & $0.656^{* *}$ & $0.604^{* *}$ & $0.299 * *$ & $0.494^{* *}$ & 0.470 ** & $0.483^{* *}$ & $-0.326^{* *}$ & -0.252 ** \\
\hline PSA & & & & & & 1 & $0.928 * *$ & $0.888^{* *}$ & 0.191 & $0.240 *$ & 0.214 * & 0.233 * & -0.18 & -0.128 \\
\hline PSG & & & & & & & 1 & $0.904^{* *}$ & 0.243 * & $0.328^{* *}$ & $0.281^{* *}$ & $0.280^{* *}$ & $-0.197 *$ & -0.137 \\
\hline HSE & & & & & & & & 1 & 0.222 * & $0.294^{* *}$ & $0.313^{* *}$ & $0.285^{* *}$ & -0.136 & -0.13 \\
\hline HPC & & & & & & & & & 1 & $0.672^{* *}$ & $0.737^{* *}$ & $0.601 * *$ & -0.091 & -0.049 \\
\hline HIE & & & & & & & & & & 1 & $0.754^{* *}$ & $0.614^{* *}$ & -0.008 & -0.005 \\
\hline HEE & & & & & & & & & & & 1 & $0.685^{* *}$ & 0.153 & 0.04 \\
\hline UFG & & & & & & & & & & & & 1 & 0.036 & -0.059 \\
\hline PEP & & & & & & & & & & & & & 1 & $0.781^{* *}$ \\
\hline UWI & & & & & & & & & & & & & & 1 \\
\hline
\end{tabular}




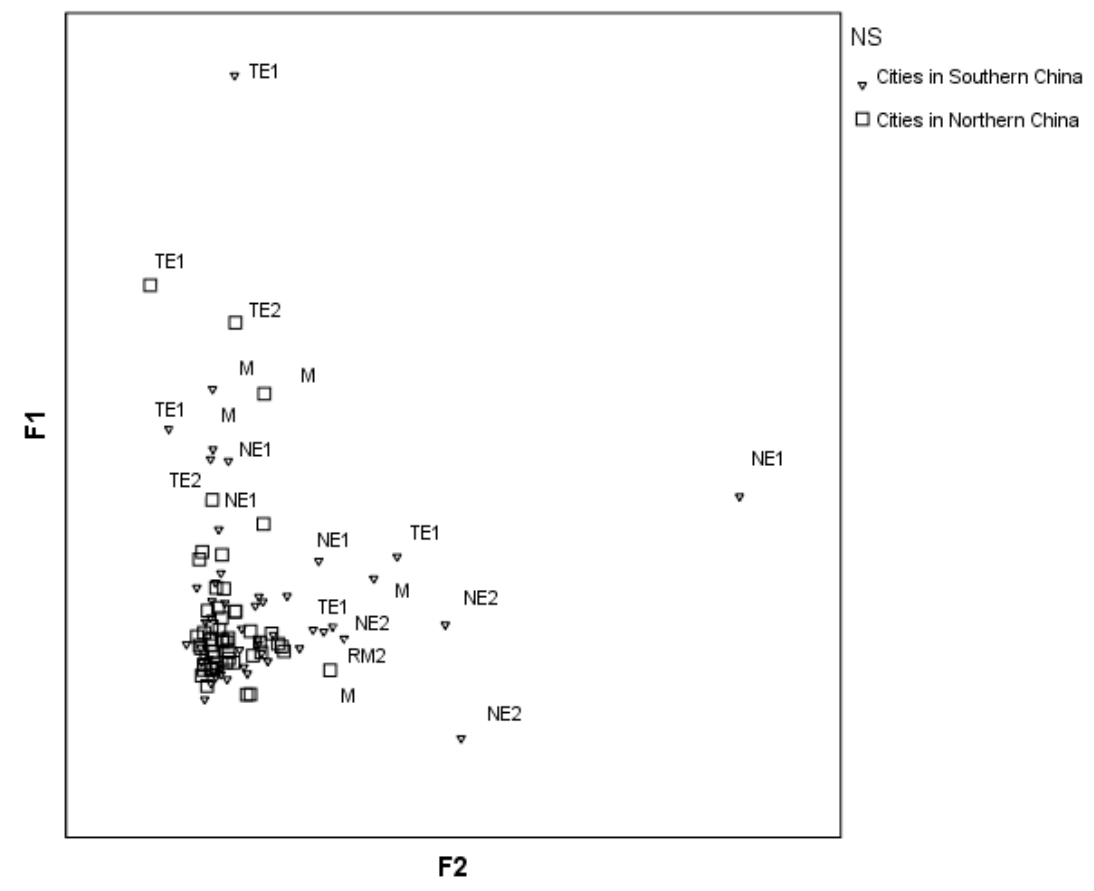

Figure 4. Regional current economic and innovation power (F1) vs. Regional economic power and Performance (F1) vs. Regional Industrial Innovation Performance (F2): Southern vs. Northern cities (NS contrast).

From Figure 6, it is also obvious that southern cities in China are more capable in terms of human resource movement and knowledge creation (F3). Especially the city of Shenzhen, marked with TE2, is a shining star city with extraordinary speed of economic development, benefiting greatly from opening up policy and more market mechanism oriented policy, is on the very top in the dimension of F3. Other cities are similar in the second cluster on F3, however, most of them are actually in the Pearl River Delta region in China, although they are marked differently as TE1, NE2 and M.

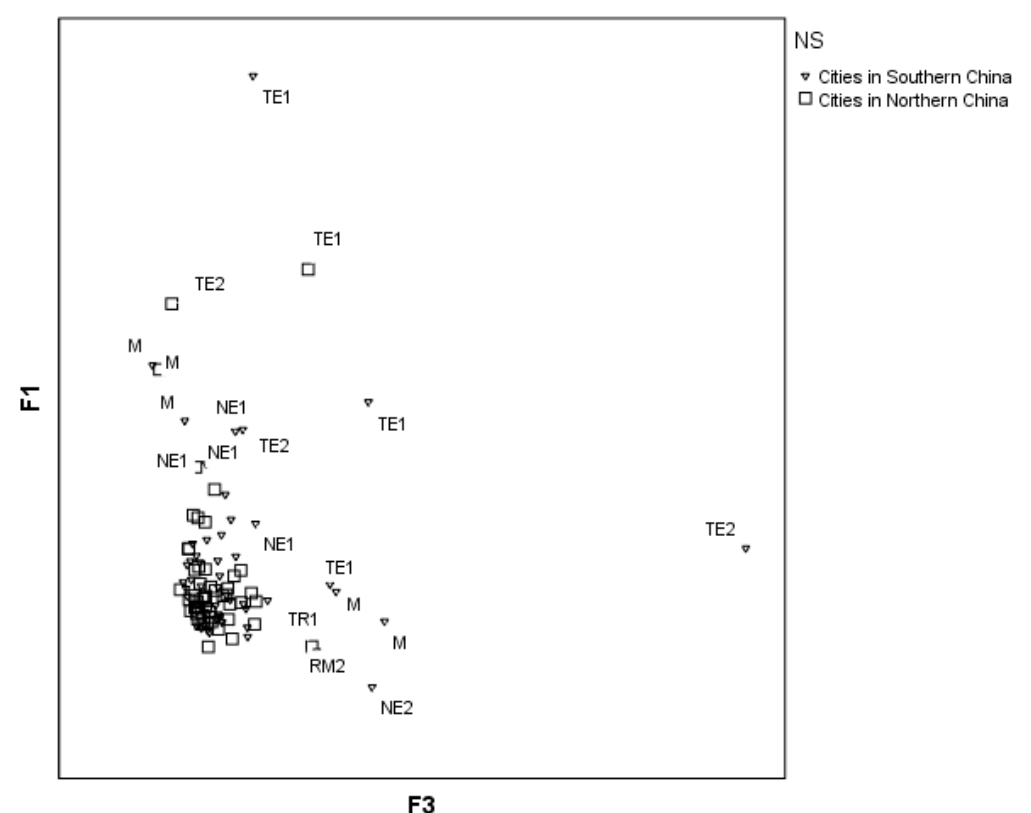

Figure 5. Regional economic power and performance (F1) vs. potentiality on human resource movement and knowledge creation (F3): southern vs. northern cities (NS contrast). 


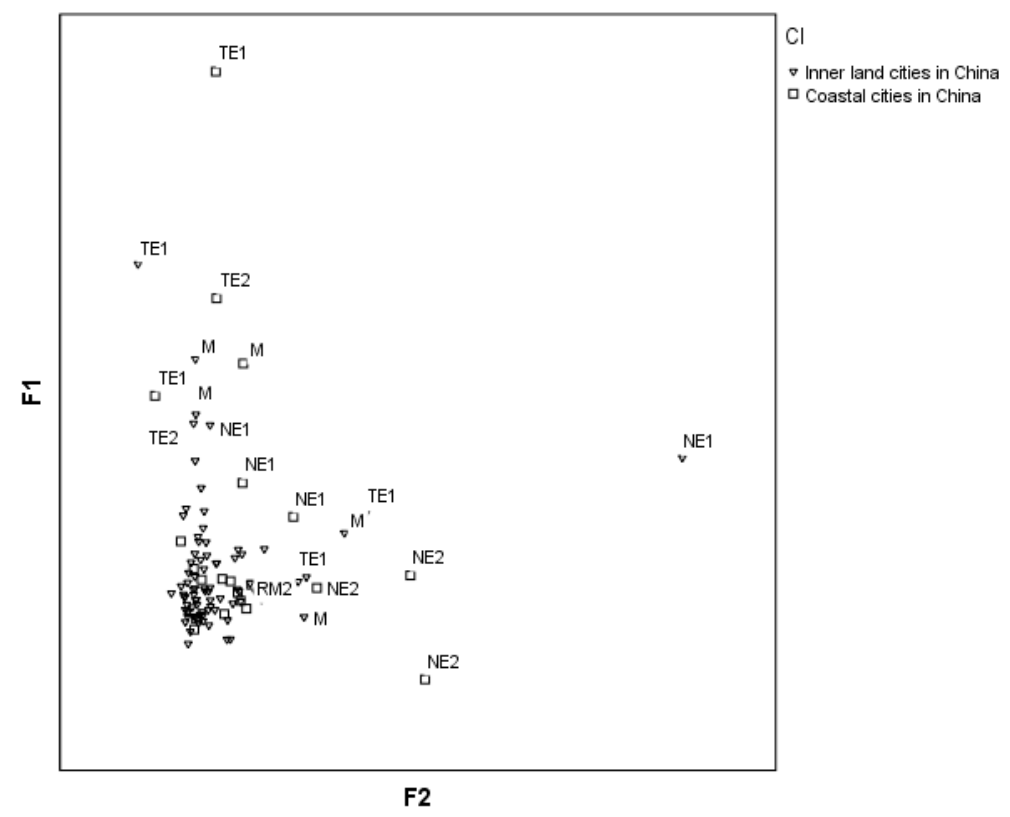

Figure 6. Regional economic power and Performance (F1) vs. Regional Industrial Innovation Performance (F2): Inner land cities vs. Coastal cities (CI contrast).

F4 is the fourth dimension on energy efficiency considerations, which indicates the nature of industries in corresponding sample cities. Since the dimension is designed in the direction positively related to the energy (electricity and water supplies)-intensive side, the dimension is correlated with strong traditional ways of production. From Figure 7, it is apparent that sample cities with lower market development position (F1) lie mostly northern in China and are among the top clusters in F4. Usually such metropolitan areas are characterized by heavy industries such as iron \& steel, coalmines and others, almost all marked TR1 or TR2. Traditions, competences and industrial cultures which have emerged in regions and cities may call for divergent applications and they may equally create divergent innovative approaches.

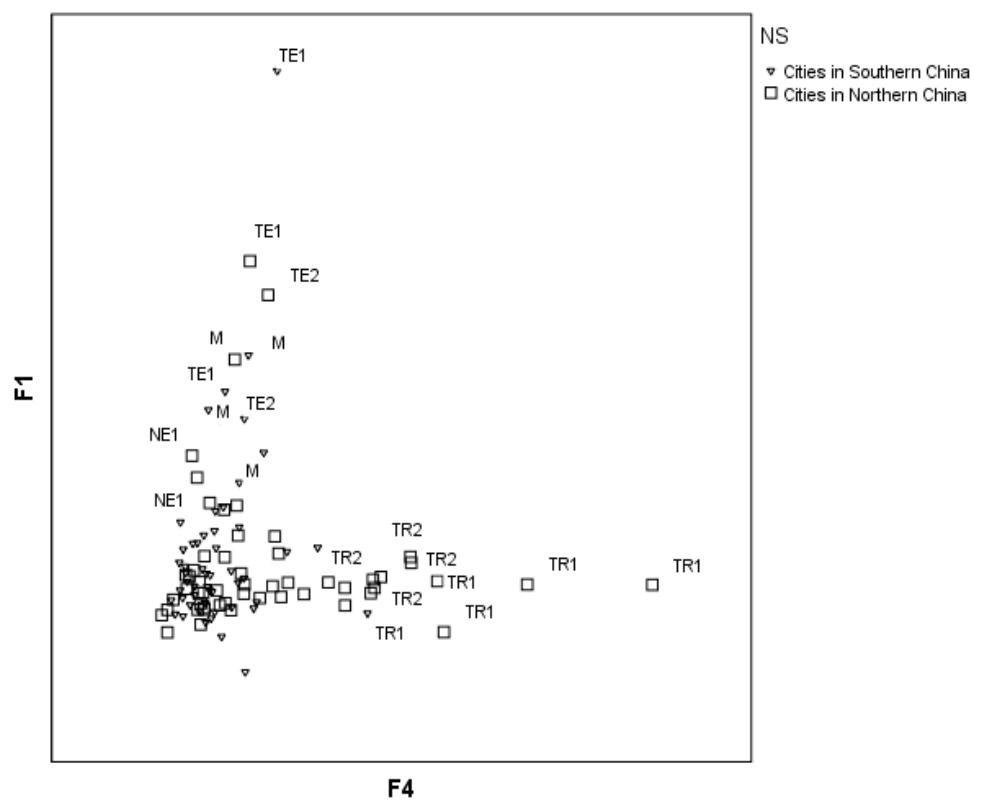

Figure 7. Regional current economic power and innovation (F1) vs. regional current industrial nature (F4): southern vs. northern cities (NS contrast). 
Based on these distributions of the sample cities, Figure 8 is provided for more significant contrast between F2 (potentiality with industrial innovation capacity) and F4 (traditional nature of production), so that there is clear and more interesting picture to show in this chart.

Although typical sample cities in TE1 and TE2 (e.g., Shanghai, Beijing and Tianjin, the top three on F1) group may lead group F1, or in current economic and innovation performances, sample cities in NE1 group (typically Suzhou, the top one on F2), stand out as more important metropolitan locations in terms of potential innovation capacity (Table 2).

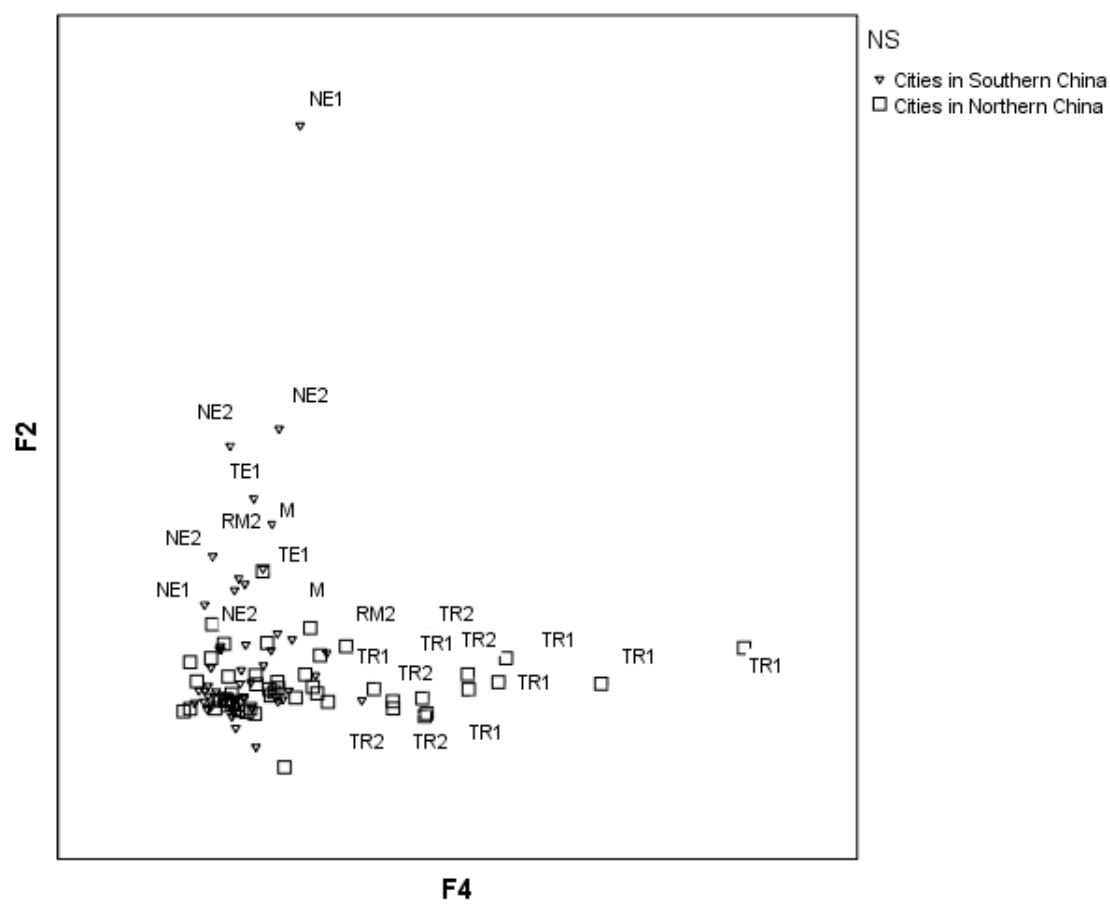

Figure 8. Regional Potential Industrial Innovation Capacity (F2) vs. Regional Current Industrial Nature (F4): Southern cities vs. Northern cities (NS contrast).

On the other hand, along the dimension of both F1 and F2, sample regions in TR1 or TR2, or in traditional manner of production, are always in low position, in terms of current and potential innovation capacity. In any case, there are large diversities among TE1 and TE2, as well as NE1 and NE2, cities in the same group can be highly different along the two dimensions, F1 and F2.

In order to show the significant locations of those sample cities in the front lines in terms of F1 (Current performance on economic and innovation output), F2 (Potential capacity in industrial innovation), F3 (Potential capacity in human resources and dynamic exchange) and F4 (Current performance in more traditional industrial nature, or more energy intensive production), the following map (Figure 9) is provided with 31 sample cities, including 10 top cities on F1 dimension and top 7 cities for each of the rest three dimensions. Areas of cities are defined according to the municipal governance. There are also black-framed samples that are cities in both top group on F2 and F3). Apparently, along the F4, all top 7 cities are TRs (Top four TR1 cities and three TR2 cities) in the map, while the top cities along F1 are TEs and most of top cities along F2 are NEs. The top 7 cities on F3 are a mixture of TEs and NEs, as well as M cities. 


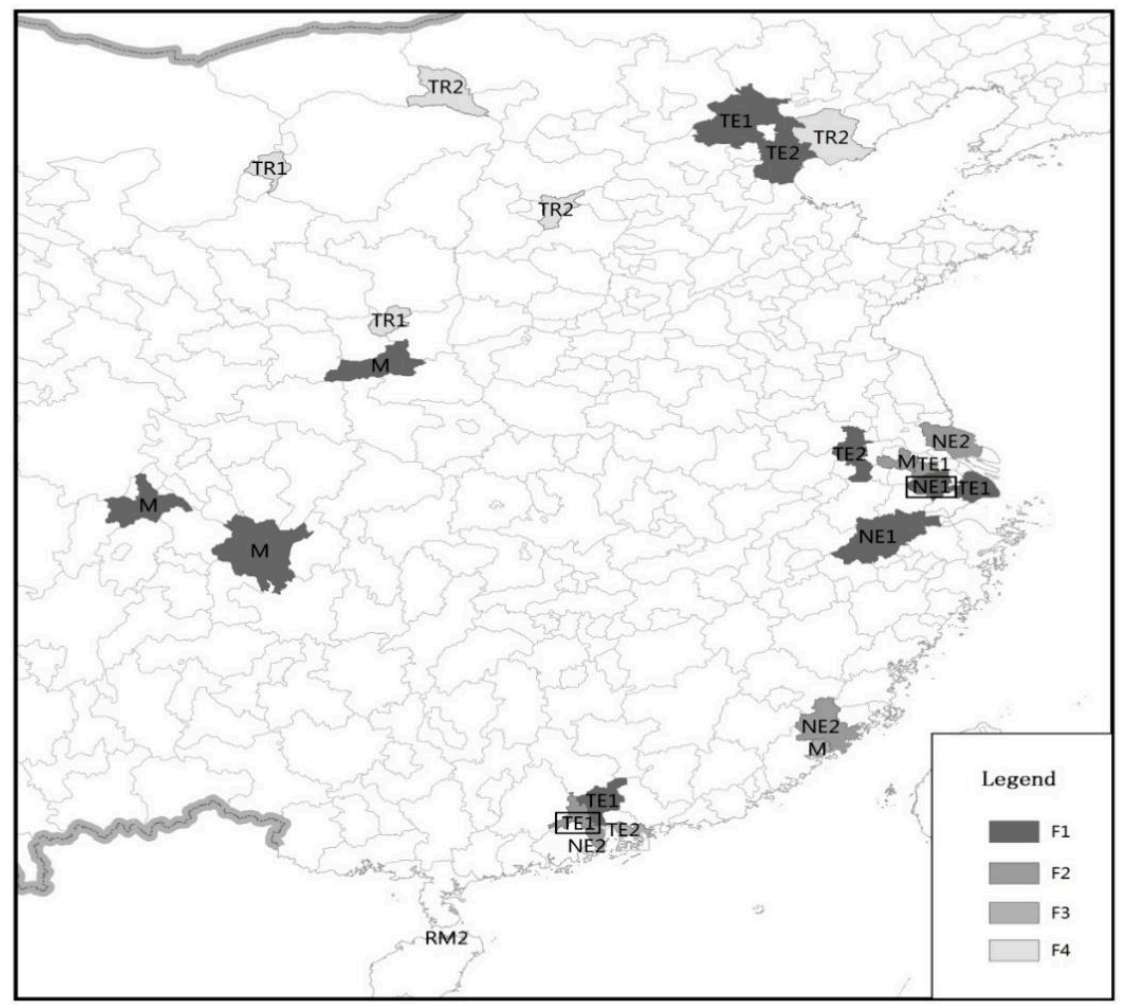

Figure 9. 31 sample top cities along F1, F2, F3 and F4 in this study.

\section{Discussions}

This research, by investigating typical Chinese cities via a two-lens framework-one from economic performance vs. energy cost and the other from current (economic and innovation) vs. potential dimension-provides a combined but also diversified picture of city-based economic development. Such diversified pattern might serve as a more precise view of the economic development at city or metropolitan level and combined view on innovation and its economic nature in sustainability terms. Numbers of factors need to be discussed for such detailed investigation of diversification in nature:

(1) Although economic and social character in the region (particularly for city case) are often important factors in sustainability studies (such as international, e.g., UNCSD standard, or national studies, e.g., Sun, X. et al. [10], Zhou et al. [54], where economic power, social capital and environmental resource are the three most frequent used dimensions for research discussion on sustainability studies), innovation measures in the region are not directly used as a major dimension for sustainability studies. This study proves that innovation activities, on the one hand, may act as positive drive for higher quality development in economic terms, on the other hand, may also improve local sustainability level, in a long run.

However, on the other hand, we are convinced again that current economic performance serves as a basis for better performance of innovation, this may be particularly true in developing countries, as local effective innovations may still be largely dependent upon enough economic volume support in those influencing industries.

(2) The research result proves that, the dimension of knowledge creation and human-resource, which should be connected more directly with sustainability level for the future development, appears to be increasingly important influencing factors on innovation, however, being diversified in China, especially in some cities with even weaker economic scale, this may reflect more independent roles in knowledge creation and human resources, which can be ecologically more relevant in emerging technology (usually less energy cost) characters. Though, in our case, accessible indicators to reflect 
such characters may be questionable on whether they are direct or indirect. In fact, current research regarding to China's case on regional economic growth, tends to connect direct indicators, such as computerization based investment [55] but such indicators should also be outcomes of knowledge creation and human resources, though neglecting other kinds of based knowledge creations. We believe that while R\&D or engineering work force in company level (which should be functioned differently from R\&D input in the Current Economic dimension) may be direct for current innovation, indicators on education (with potential knowledge-creation effect) may be indirect but still sustainability relevant, as shown in study by Grinstdsted [56]. In any case, indicators selected in this research can, show the potential and current innovation.

Particularly, in this research, we added volume and density of communication by population, which can indicate the frequency of information exchange by the population in the region, which can be understood as basic conditions for knowledge creation in the local regions, especially as the basis for local networking among individuals and even institutions. This is also consistent with current sustainability studies on knowledge transfers [57].

(3) Characters of industrial tradition, measured by energy intensiveness in the region, are taken into account in this study. This can clearly address the nature of industrial heritage or industrial routine in the region. More ontological investigation framework may include energy character, however, usually on positive side for new energy or energy technology development (such as study on ontological perspective over sustainable development [58]). In other literature, such kind of measures to include both positive and negative sides are not so much used, even less used together with innovation performance as the contrasted dimension.

Based on our combined two lens investigation framework, following interesting points are worth noting, in contrast with current studies on sustainability:

(1) Cities are rather clustered in innovation and sustainable development sense, across regions. Although current studies on eco-innovation in Chinese case in geographical regions provide larger scope picture across geographical regions in coastal vs. Inner land regions [59], innovation and sustainability in city level in our study proves to be more characterized in more diverse pattern, in clusters. For example, while sample cities are diversified in differentiated measures, some typical top sample cities in larger economic power or in newly styled (greener use of energy) ranking are rather clustered in metropolitan belt or clusters rather than in isolated situation. Such as, Shanghai (marked with TE1) and Suzhou (NE1), the two cities are geographically very close in Yangtze River Delta, both are ranked top in Figures 6 and 7 respectfully. There are other similar cases in Pearl River Delta region where Guangzhou, Shenzhen and Zhongshan, as well as others are closer in their position along F1, F2, or F3. This finding can reveal that metropolitan cities are rather clustered and characterized in groups, along current and potentiality measure, especially when such characters appear high and strong. Such facts also imply that city based innovation and sustainability study are more meaningful than studies in provincial level or investigation over larger geographical scope.

(2) Energy intensiveness and related industrial traditions are one of the major concerns in this study, through investigation Lens I and combined effect shown on Lens II. It is indeed that there are higher correlations between energy intensive use and more traditional industrial output among those sample cities in China, which is more relevant in developing economies' case, rather than other studies on environmental sustainability [60]. In this study, intensiveness of energy consumption may occur in higher production value regions, however, those areas with lower production value together with higher intensity of energy use can be highly relevant to typical traditional industrial metropolitan regions, mostly with long term histories of rather a path-locked production pattern. Such pattern may clearly inform negative signs of sustainability in the region, in developing economies. Although, due to diversified mode of city based economic development, production characters may not be simply black or white for all cities, other factors, including innovation resources (e.g., human resource) and possibly geographically embedded culture (such as coastal vs. Inner land, or southern vs. Northern regions), may add extra information to identify diversified but also modelled economic development 
route in the sample cities. Therefore, nature of energy use, including energy efficiency technologies, as positive signs and energy intensiveness in negative side, might together serve as important measure for finding active innovation characters with sustainability nature in local industries.

(3) Naturally, there are individual cities that are separated in geographical terms but we still find larger numbers of cities which can be characterized along the four dimensions for positioning their statues in terms of their innovation and sustainability. Such "residual effect" of grouping or clustering character also reveals that production value, market performance and even current innovation performance in the region, are not enough to explain different innovation capacity for the future, particularly the diversity function of innovation and sustainability in geographical sense. However, energy intensive character can explain- to a certain extent- the characters of regional innovation in this study. Another kind of business cultural factor, geographical location toward north or south in China, may also respond market development traditions for the sample cities, therefore may be used to explain diversities of innovation in metropolitan level studies.

There are still limitations in this study, primarily, (1) Due to limited source and to limited time of studies, the investigation to support the framework is only based on data in 2013, however, since we mainly focus on the relative position of each sample city and only relative measures are used in this study, such relative position is usually stable, especially for those sample cities in top ranks, still, different time phase in a longer period may give better view on the dynamic motion of the development on both innovation and sustainability. (2) In this study, we particularly show characteristics of top sample cities along the four dimensions of the investigation framework. Due to a combined effect, such top sample cities are those well known economic and innovative stars in the Chinese economy; however, other sample cities that are further inland, far to the south and to the far west of China, are not discussed in more detail, except for a limited number of sample cities in TR regions. These untouched issues may be further explored and studied with better and detailed information in the future.

\section{Conclusions}

Based on the investigation over Lens I on economic performance with energy intensiveness, the investigation through Lens II on diversities of innovation over 106 sample cities in China shows that the actual position on current and potential dimensions of sample cities in China can reflect the nature of metropolitan-area based diversities of innovation and of possible correlated factors related to regional sustainable development. Specifically, (1) In terms of human capital and knowledge creation level, those sample cities in NE (New Economy Region) or TE (Top Economy Region) groups are on the top rank. (2) Southern vs. northern cities prove to be a more important dimension for a detailed investigation on industrial tradition. Diversified innovation and sustainability in China southern cities, usually with more open market and dynamic characters in market culture, are more active to improve local production via innovation. (3) Economic strength in production value and market openness can certainly explain sample cities' higher level of innovation capacity, in current and potential measure but only limited to numbers of extra-large cities, such as Beijing, Shanghai, Tianjin and some others. Larger sums of sample cities in terms of production value and economically openness measures are actually diversified along the current and potential innovation capacity, revealing other factors behind to explain innovation. (4) Energy intensive character can be found in larger and key manufacturing cities with higher economic power, or in highly traditional industries with lower economic performance. But if combined with efficiency measures, it is obvious that regions and cities with less efficiency level in energy costs are less capable of innovation, both in current and in potential terms and therefore facing challenging issues on sustainability.

Acknowledgments: The authors would like to thank the three anonymous referees for their constructive comments and evaluations of this paper and thank research opportunity and support provided by NSFC (Natural Science Foundation of China) on the project (project number 71332003).

Author Contributions: Xiangdong Chen designed the research framework, with the necessary literature review and related data dimensions and wrote the English version of the research paper; and made major revisions to 
the paper; Ruixi Li collected necessary data and performed the sample data processing and extracted the major results for the updated version; Xin Niu did the original version of the data processing and helped to produce the necessary charts for this paper; Ulrich Hilpert provided very useful suggestions on the research framework and other topics of the research; Valerie Hunstock revised this paper and improved the professional English version.

Conflicts of Interest: The authors declare no conflict of interest.

\section{Appendix A}

Table A1. Typical economic and innovation indicators for 106 sample cities in China. (Ranked by production output).

\begin{tabular}{|c|c|c|c|c|}
\hline City & Local Production Output & Population & FDI & Granted Patent \\
\hline Shanghai & 0.05300 & 0.02487 & 0.07870 & 0.10085 \\
\hline Beijing & 0.04696 & 0.02261 & 0.04168 & 0.14250 \\
\hline Guangzhou & 0.03559 & 0.01433 & 0.02458 & 0.03614 \\
\hline Shenzhen & 0.03401 & 0.00501 & 0.02710 & 0.04627 \\
\hline Tianjin & 0.03386 & 0.01731 & 0.07782 & 0.02749 \\
\hline Suzhou & 0.03155 & 0.01129 & 0.04750 & 0.03660 \\
\hline Chongqing & 0.02996 & 0.05827 & 0.05459 & 0.01956 \\
\hline Chengdu & 0.02137 & 0.02045 & 0.04452 & 0.02882 \\
\hline Wuhan & 0.02102 & 0.01432 & 0.02303 & 0.03138 \\
\hline Hangzhou & 0.02049 & 0.01221 & 0.02571 & 0.04623 \\
\hline Wuxi & 0.01988 & 0.00819 & 0.02078 & 0.02357 \\
\hline Qingdao & 0.01918 & 0.01341 & 0.02384 & 0.01401 \\
\hline Nanjing & 0.01891 & 0.01113 & 0.02141 & 0.04396 \\
\hline Dalian & 0.01839 & 0.01029 & 0.06401 & 0.01086 \\
\hline Foshan & 0.01737 & 0.00658 & 0.01218 & 0.00915 \\
\hline Shenyang & 0.01734 & 0.01263 & 0.03008 & 0.01189 \\
\hline Ningbo & 0.01729 & 0.01007 & 0.01478 & 0.01958 \\
\hline Changsha & 0.01681 & 0.01151 & 0.01543 & 0.02366 \\
\hline Tangshan & 0.01539 & 0.01293 & 0.00638 & 0.00264 \\
\hline Zhengzhou & 0.01457 & 0.01869 & 0.01777 & 0.01134 \\
\hline Yantai & 0.01387 & 0.01133 & 0.00731 & 0.00528 \\
\hline Jinan & 0.01262 & 0.01062 & 0.00632 & 0.02064 \\
\hline Quanzhou & 0.01241 & 0.01208 & 0.00684 & 0.00310 \\
\hline Nantong & 0.01197 & 0.01334 & 0.01143 & 0.00813 \\
\hline Harbin & 0.01195 & 0.01732 & 0.00985 & 0.01742 \\
\hline Shijiazhang & 0.01182 & 0.01752 & 0.00440 & 0.00500 \\
\hline Changchun & 0.01170 & 0.01319 & 0.01908 & 0.01056 \\
\hline$X_{i}{ }^{\prime} a n$ & 0.01147 & 0.01387 & 0.01284 & 0.03707 \\
\hline Fuzhou & 0.01108 & 0.01142 & 0.00694 & 0.01026 \\
\hline Hefei & 0.01094 & 0.01238 & 0.00858 & 0.01465 \\
\hline Xuzhou & 0.01055 & 0.01726 & 0.00881 & 0.00494 \\
\hline Weifang & 0.01054 & 0.01532 & 0.00398 & 0.00415 \\
\hline Daqing & 0.01051 & 0.00491 & 0.00261 & 0.00155 \\
\hline Changzhou & 0.01043 & 0.00636 & 0.01742 & 0.01173 \\
\hline Wenzhou & 0.00964 & 0.01395 & 0.00206 & 0.00516 \\
\hline Shaoxing & 0.00960 & 0.00768 & 0.00494 & 0.00524 \\
\hline Zibo & 0.00934 & 0.00738 & 0.00259 & 0.00518 \\
\hline Baotou & 0.00895 & 0.00390 & 0.00707 & 0.00103 \\
\hline Jining & 0.00838 & 0.01476 & 0.00399 & 0.00310 \\
\hline Handan & 0.00794 & 0.01731 & 0.00415 & 0.00158 \\
\hline Kunming & 0.00791 & 0.00947 & 0.00823 & 0.00757 \\
\hline Nanchang & 0.00788 & 0.00885 & 0.01368 & 0.00410 \\
\hline Luoyang & 0.00783 & 0.01237 & 0.01033 & 0.00664 \\
\hline Yangzhou & 0.00770 & 0.00799 & 0.01108 & 0.00376 \\
\hline Taizhou & 0.00765 & 0.01030 & 0.00246 & 0.00585 \\
\hline Jiaxing & 0.00759 & 0.00600 & 0.00923 & 0.00362 \\
\hline Xiamen & 0.00740 & 0.00333 & 0.00826 & 0.00773 \\
\hline Baoding & 0.00715 & 0.02043 & 0.00285 & 0.00328 \\
\hline Tai'an & 0.00669 & 0.00974 & 0.00088 & 0.00183 \\
\hline
\end{tabular}


Table A1. Cont.

\begin{tabular}{|c|c|c|c|c|}
\hline City & Local Production Output & Population & FDI & Granted Patent \\
\hline Yichang & 0.00659 & 0.00695 & 0.00119 & 0.00175 \\
\hline Nanning & 0.00657 & 0.01244 & 0.00082 & 0.00364 \\
\hline Hohhot & 0.00650 & 0.00401 & 0.00320 & 0.00234 \\
\hline Zhongshan & 0.00641 & 0.00265 & 0.00436 & 0.00416 \\
\hline Jilin & 0.00638 & 0.00751 & 0.00367 & 0.00116 \\
\hline Anshan & 0.00638 & 0.00611 & 0.00661 & 0.00500 \\
\hline Taiyuan & 0.00607 & 0.00638 & 0.00405 & 0.00862 \\
\hline Yueyang & 0.00578 & 0.00999 & 0.00118 & 0.00097 \\
\hline Changde & 0.00535 & 0.01096 & 0.00213 & 0.00083 \\
\hline Urumchi & 0.00526 & 0.00449 & 0.00100 & 0.00024 \\
\hline Wuhu & 0.00492 & 0.00668 & 0.00694 & 0.00667 \\
\hline Zhanjiang & 0.00489 & 0.01369 & 0.00045 & 0.00102 \\
\hline Liuzhou & 0.00478 & 0.00649 & 0.00184 & 0.00111 \\
\hline Zhuzhou & 0.00463 & 0.00690 & 0.00302 & 0.00135 \\
\hline Zaozhuang & 0.00447 & 0.00688 & 0.00074 & 0.00106 \\
\hline Huzhou & 0.00437 & 0.00456 & 0.00532 & 0.00493 \\
\hline Lianyungang & 0.00421 & 0.00891 & 0.00380 & 0.00220 \\
\hline Xianyang & 0.00413 & 0.00920 & 0.00037 & 0.00127 \\
\hline Chifeng & 0.00412 & 0.00804 & 0.00006 & 0.00028 \\
\hline Anyang & 0.00411 & 0.01034 & 0.00164 & 0.00091 \\
\hline Lanzhou & 0.00411 & 0.00560 & 0.00004 & 0.00478 \\
\hline Jiaozuo & 0.00407 & 0.00640 & 0.00311 & 0.00169 \\
\hline Zhuhai & 0.00395 & 0.00186 & 0.00750 & 0.00255 \\
\hline Pingdingshan & 0.00393 & 0.00951 & 0.00194 & 0.00094 \\
\hline Guilin & 0.00390 & 0.00910 & 0.00022 & 0.00317 \\
\hline Shantou & 0.00374 & 0.00929 & 0.00068 & 0.00188 \\
\hline Jiujiang & 0.00373 & 0.00886 & 0.00512 & 0.00068 \\
\hline Qujing & 0.00368 & 0.01111 & 0.00021 & 0.00029 \\
\hline Baoji & 0.00361 & 0.00669 & 0.00031 & 0.00116 \\
\hline Rizhao & 0.00355 & 0.00502 & 0.00218 & 0.00071 \\
\hline Mianyang & 0.00354 & 0.00951 & 0.00109 & 0.00328 \\
\hline Changzhi & 0.00349 & 0.00586 & 0.00145 & 0.00094 \\
\hline Xiangtan & 0.00337 & 0.00509 & 0.00304 & 0.00211 \\
\hline Yan'an & 0.00334 & 0.00410 & 0.00010 & 0.00017 \\
\hline Yibin & 0.00326 & 0.00953 & 0.00024 & 0.00064 \\
\hline Jinzhou & 0.00326 & 0.00537 & 0.00520 & 0.00079 \\
\hline Fushun & 0.00325 & 0.00382 & 0.00065 & 0.00059 \\
\hline Ma onshan & 0.00324 & 0.00398 & 0.00694 & 0.00255 \\
\hline Linfen & 0.00321 & 0.00741 & 0.00071 & 0.00067 \\
\hline Kaifeng & 0.00317 & 0.00949 & 0.00128 & 0.00049 \\
\hline Qiqihaer & 0.00309 & 0.00974 & 0.00181 & 0.00069 \\
\hline Yinchuan & 0.00302 & 0.00291 & 0.00036 & 0.00121 \\
\hline Qinhuangdao & 0.00299 & 0.00508 & 0.00325 & 0.00181 \\
\hline Benxi & 0.00292 & 0.00267 & 0.00239 & 0.00029 \\
\hline Luzhou & 0.00271 & 0.00881 & 0.00027 & 0.00095 \\
\hline Mudanjiang & 0.00258 & 0.00452 & 0.00068 & 0.00034 \\
\hline Datong & 0.00245 & 0.00557 & 0.00109 & 0.00054 \\
\hline Shaoguan & 0.00238 & 0.00569 & 0.00089 & 0.00034 \\
\hline Xining & 0.00224 & 0.00346 & 0.00015 & 0.00065 \\
\hline Haikou & 0.00215 & 0.00282 & 0.00235 & 0.00365 \\
\hline Karamay & 0.00213 & 0.00066 & 0.00009 & 0.00033 \\
\hline Panzhihua & 0.00194 & 0.00195 & 0.00054 & 0.00191 \\
\hline Beihai & 0.00166 & 0.00293 & 0.00027 & 0.00030 \\
\hline Yangquan & 0.00158 & 0.00230 & 0.00122 & 0.00016 \\
\hline Shizuishan & 0.00108 & 0.00129 & 0.00000 & 0.00027 \\
\hline Tongchuan & 0.00072 & 0.00149 & 0.00016 & 0.00006 \\
\hline Jinchang & 0.00064 & 0.00081 & 0.00000 & 0.00020 \\
\hline
\end{tabular}

Note: The data in Table A1 is the ratio to sum of value on each corresponding indicator. Data source: China City Statistical Yearbook, 2013; patent data are collected from SIPO website. 


\section{References}

1. Acs, Z.J.; Anselin, L.; Varga, A. Patents and innovation counts as measures of regional production of new knowledge. Res. Policy 2002, 31, 1069-1085. [CrossRef]

2. Malecki, E.J. Science, technology, and regional economic development: Review and prospects. Res. Policy 1981, 10, 312-334. [CrossRef]

3. Sweeney, G.P. Innovation, Entrepreneurs, and Regional Development; Burns \& Oates: London, UK, 1987.

4. Hall, P.; Markusen, A. High technology and regional-urban policy. In Silicon Landscapes; Allen and Unwin: Crows Nest, Australia, 1985; pp. 144-151.

5. Stöhr, W.B. Regional innovation complexes. Pap. Reg. Sci. 1986, 59, 29-44. [CrossRef]

6. Varga, A. Time-space patterns of US innovation: Stability or change? In Innovation, Networks and Localities; Fischer, M.M., Suarez-Villa, L., Steiner, M., Eds.; Springer: Berlin/Heidelberg, Germany, 1999; pp. $215-234$. ISBN 978-3-642-63631-8.

7. Hilpert, U.; Hickie, D.; Drüke, H. Old and traditional industrial regions on the archipelago EuropeGovernmental systems and regionalization of innovation. In Regionalisation of Globalised Innovation: Locations for Advanced Industrial Development and Disparities in Participation; Hilpert, U., Ed.; Routledge: New York, NY, USA, 2003; Volume 37, ISBN 0-203-44797-2.

8. Caniëls, M.C. Knowledge Spillovers and Economic Growth: Regional Growth Differentials across Europe; Edward Elgar Publishing: Cheltenham, UK, 2000.

9. Shen, L.; Cheng, S.; Gunson, A.J.; Wan, H. Urbanization, sustainability and the utilization of energy and mineral resources in China. Cities 2005, 22, 287-302. [CrossRef]

10. Sun, X.; Liu, X.S.; Li, F.; Tao, Y. Comprehensive evaluation of sustainable development for different scale cities in China. Acta Ecol. Sin. 2016, 36, 5590-5600.

11. Bell, G.G. Clusters, Networks and Firm Innovativeness. Strateg. Manag. J. 2005, 26, 287-295. [CrossRef]

12. Baptista, R.; Swann, P. Do firms in clusters innovate more? Res. Policy 1998, 27, 525-540. [CrossRef]

13. Polanyi, M. The Tacit Dimension; Routledge \& Kegan Paul: London, UK, 1996.

14. Dosi, G. Sources, procedures, and microeconomic effects of innovation. J. Econ. Lit. 1988, 26, 1120-1171.

15. Feldman, M.P. Knowledge complementarity and innovation. Small Bus. Econ. 1994, 6, 363-372. [CrossRef]

16. Acs, Z. Regional Innovation, Knowledge, and Global Change; Frances Pinter: New York, NY, USA, 2000.

17. Braczyk, H.J.; Cooke, P.N.; Heidenreich, M. Regional Innovation Systems: The Role of Governances in a Globalized World; Psychology Press: London, UK, 1998; ISBN 0-203-27671X.

18. De la Mothe, J.; Paquet, G. Local and regional systems of innovation as learning socio-economies. Econ. Sci. Technol. Innov. 1998, 14, 1-18.

19. Padmore, T.; Gibson, H. Modelling systems of innovation: II. A framework for industrial cluster analysis in regions. Res. Policy 1998, 26, 625-641. [CrossRef]

20. Padmore, T.; Schuetze, H.; Gibson, H. Modeling systems of innovation: An enterprise-centered view. Res. Policy 1998, 26, 605-624. [CrossRef]

21. Fischer, M.M.; Diez, J.R.; Snickars, F. Metropolitan Innovation Systems: Theory and Evidence from Three Metropolitan Regions in Europe. Eur. Plan. Stud. 2002, 10, 275-279.

22. Liu, X. Analysis and report on regional innovation capacity in China: 2004-2005. Study Sci. Sci. Technol. 2005, 12, 5-14. (In Chinese)

23. Hao, Y.; Tang, J. Regional innovation capacity and its constrain factors, province based panel data investigation between 1997 and 2007. Manag. J. 2009, 6, 1182-1187. (In Chinese)

24. Zhou, T.; Kuang, J.; Pan, Y. China City Innovation Report Blue Book; Hong Qi Press: Changchun, China, 2015. (In Chinese)

25. Cooke, P. The new wave of regional innovation networks: Analysis, characteristics and strategy. Small Bus. Econ. 1996, 8, 159-171. [CrossRef]

26. Nelson, R. National Innovation Systems-A Comparative Analysis; Oxford University Press: Oxford, UK, 1993.

27. Buesa, M.; Heijs, J.; Baumert, T. The determinants of regional innovation in Europe: A combined factorial and regression knowledge production function approach. Res. Policy 2010, 39, 722-735. [CrossRef]

28. Fritsch, M.; Slavtchev, V. How does industry specialization affect the efficiency of regional innovation systems? Ann. Reg. Sci. 2010, 45, 87-108. [CrossRef] 
29. Broekel, T. Collaboration intensity and regional innovation efficiency in Germany-A conditional efficiency approach. Ind. Innov. 2012, 19, 155-179. [CrossRef]

30. Deyle, H.G.; Grupp, H. Commuters and the regional assignment of innovative activities: A methodological patent study of German districts. Res. Policy 2005, 34, 221-234. [CrossRef]

31. An, Z. Regulation Reformation and Organizational Change on Harmonizing Development of Metropolitan Regions; Economic Science Press: Beijing, China, 2006. (In Chinese)

32. Xie, F.J.; Xu, H.M. Study on the modes of metropolitan innovation system. China Econ. Rev. 2007, 3, 1-7.

33. Xie, F.J. Research on the Operation Mechanism of the Innovation System of the Yangtze River Delta Metropolitan Area; Zhongpu Yangtze River Delta High-Level Forum: Kunshan, China, 2010.

34. Cooke, P.; Morgan, K. Learning through Networking: Regional Innovation and the Lessons of Baden-Wurttemberg; Regional Industrial Research Report No. 5; University of Wales: Cardiff, UK, 1990.

35. Hilpert, U.; Smith, H.L. Networking of Regionalised Innovative Labour Market; Routledge: Abingdon-on-Thames, UK, 2013.

36. Wang, J. Networking environment: The new change of industrial organization. Strateg. Manag. J. 1997, 3, 109-144. (In Chinese)

37. Gai, W.; Wang, J. Function of regional networking on small high tech companies in China. China Soft Sci. 1999, 9, 102-106. (In Chinese)

38. Jaffe, A.B. Real Effects of Academic Research. Am. Econ. Rev. 1989, 79, 957-970.

39. Griliches, Z. The Search for R\&D Spillovers. Scand. J. Econ. 1992, 94, $29-47$.

40. Verspagen, B. Uneven growth between rivals: Informal know-how trading. Res. Policy 1993, 16, $291-302$.

41. Pavitt, K.; Patel, P. Uneven (and divergent) technological accumulation among advanced countries. Ind. Corp. Chang. 1994, 3, 59-787.

42. Spangenberg, J.H. Environmental space and the prism of sustainability: Frameworks for indicators measuring sustainable development. Ecol. Indic. 2002, 2, 295-309. [CrossRef]

43. Spangenberg, J.H.; Bonniot, O. Sustainability Indicators: A Compass on the Road toward Sustainability; Wuppertal Papers No. 81; Wuppertal Inst. für Klima, Umwelt, Energie: Wuppertal, Germany, 1998.

44. Feng, Z.; Chen, W. Environmental Regulation, Green Innovation, and Industrial Green Development: An Empirical Analysis Based on the Spatial Durbin Model. Sustainability 2018, 10, 223. [CrossRef]

45. Johnson, W.H.A.; Liu, Q. Patenting and the role of technology markets in regional innovation in China: An empirical analysis. J. High Technol. Manag. Res. 2011, 22, 14-25. [CrossRef]

46. Chen, K.; Kenney, M. Universities/research institutes and regional innovation systems: The cases of Beijing and Shenzhen. World Dev. 2007, 35, 1056-1074. [CrossRef]

47. Li, X. China's regional innovation capacity in transition: An empirical approach. Res. Policy 2009, 38, 338-357. [CrossRef]

48. Wang, J.; Fang, C. New-type driving forces of urban agglomerations development in China. Geogr. Res. 2011, 30, 335-347.

49. Xiao, Z.; Du, X.; Wu, C. Regional Difference and Evolution and Convergence of Innovation Capability in China: Research on Space and Factorial Levels. Sustainability 2017, 9, 1644. [CrossRef]

50. Zhang, Y.; Na, S.; Niu, J.; Jiang, B. The Influencing Factors, Regional Difference and Temporal Variation of Industrial Technology Innovation: Evidence with the FOA-GRNN Model. Sustainability 2018, 10, 187. [CrossRef]

51. Yu, C.; Zhang, Z.; Lin, C.; Wu, Y.J. Knowledge Creation Process and Sustainable Competitive Advantage: The Role of Technological Innovation Capabilities. Sustainability 2017, 9, 2280. [CrossRef]

52. Zhang, B.; Yao, F.; Zhang, J.; Jiang, L. Technology Transfer from Formal Soviet Union to China, 1949-1966; Shandong Press: Jinan, China, 2004. (In Chinese)

53. Wu, Q.; Ning, Y. Analysis on City Networking in China-From perspective of electronic and information companies. Geogr. Stud. 2012, 31, 207-219. (In Chinese)

54. Zhou, P.; Bai, Y.; Ma, W.; Wu, R.; Zhang, R.; Zuo, N. Evolvement of Spatial Pattern of Sustainable Development Efficiency and Its Influencing Factors for Resource-based Cities in China. J. Desert Res. 2016, 36, 1489-1495.

55. Li, Q.; Wu, Y. Intangible capital in Chinese regional economies: Measurement and analysis. China Econ. Rev. 2017. [CrossRef]

56. Grindsted, T.S. Regional planning, sustainability goals and the mitch-match between educational practice and climate, energy and business plans. J. Clean. Prod. 2018, 171, 1681-1690. [CrossRef] 
57. When, U.; Montalvo, C. Knowledge transfer dynamics and innovation: Behavior, interactions and aggregated outcomes. J. Clean. Prod. 2018, 171, S56-S68. [CrossRef]

58. Cancino, C.A.; La Paz, A.I.; Ramaprasad, A.; Syn, T. Technological innovation for sustainable growth: An ontological perspective. J. Clean. Prod. 2018, 179, 31-41. [CrossRef]

59. Chen, J.; Cheng, J.; Dai, S. Regional eco-innovation in China: An analysis of eco-innovation levels and influencing factors. J. Clean. Prod. 2017, 153, 1-14. [CrossRef]

60. Gliedt, T.; Hoicka, C.E.; Jackson, N. Innovation intermediaries accelerating environmental sustainability transitions. J. Clean. Prod. 2017, 174, 1247-1261. [CrossRef] 